\title{
Large-Scale Analysis of Global Gridded Precipitation and Temperature Datasets for Climate Change Impact Studies
}

\author{
Mostafa TARek, ${ }^{a, b}$ François P. Brissette, ${ }^{a}$ And Richard Arsenault ${ }^{a}$ \\ ${ }^{a}$ Hydrology, Climate and Climate Change Laboratory, École de Technologie Supérieure, Montreal, Quebec, Canada \\ ${ }^{\mathrm{b}}$ Department of Civil Engineering, Military Technical College, Cairo, Egypt
}

(Manuscript received 20 April 2020, in final form 4 September 2020)

\begin{abstract}
Currently, there are a large number of diverse climate datasets in existence, which differ, sometimes greatly, in terms of their data sources, quality control schemes, estimation procedures, and spatial and temporal resolutions. Choosing an appropriate dataset for a given application is therefore not a simple task. This study compares nine global/nearglobal precipitation datasets and three global temperature datasets over 3138 North American catchments. The chosen datasets all meet the minimum requirement of having at least 30 years of available data, so they could all potentially be used as reference datasets for climate change impact studies. The precipitation datasets include two gauged-only products (GPCC and CPC-Unified), two satellite products corrected using ground-based observations (CHIRPS V2.0 and PERSIANN-CDR V1R1), four reanalysis products (NCEP CFSR, JRA55, ERA-Interim, and ERA5), and one merged product (MSWEP V1.2). The temperature datasets include one gauge-based (CPC-Unified) and two reanalysis (ERAInterim and ERA5) products. High-resolution gauge-based gridded precipitation and temperature datasets were combined as the reference dataset for this intercomparison study. To assess dataset performance, all combinations were used as inputs to a lumped hydrological model. The results showed that all temperature datasets performed similarly, albeit with the CPC performance being systematically inferior to that of the other three. Significant differences in performance were, however, observed between the precipitation datasets. The MSWEP dataset performed best, followed by the gauge-based, reanalysis, and satellite datasets categories. Results also showed that gauge-based datasets should be preferred in regions with good weather network density, but CHIRPS and ERA5 would be good alternatives in data-sparse regions.
\end{abstract}

KEYWORDS: Hydrology; Hydrometeorology; Databases; Satellite observations

\section{Introduction}

Climate change impact assessments require future climate scenarios developed at adequately high spatial and temporal resolutions. Although general circulation models (GCMs) are typically sourced for future climate projections, their spatial resolution is often too coarse for finescale climate studies (Ahmed et al. 2013). Consequently, spatial downscaling and/or bias correction approaches are normally used to bring biascorrected GCM simulation information to the appropriate scale before it is used in impact models. This procedure requires a reference climate dataset generally consisting of precipitation and temperature data to ensure that the downscaling and/or bias correcting steps preserve the main characteristics of the reference climate at the finer scale. An often limiting additional requirement of reference datasets is that they should cover a time period long enough to filter out high-frequency internal variability (e.g., Deser et al. 2012). A 30-yr period is generally favored as defined by the World Meteorological Organization, even though periods as short as 20 years have been used in the literature (e.g., Martel et al. 2018). It is important that the chosen dataset represent the true state of the reference climate as closely as possible, since any deficiency in the reference dataset would be transferred to the future climate scenario.

Notwithstanding the limitations associated with meteorological stations as reference datasets, such as missing records,

Corresponding author: Mostafa Tarek, mostafa-tarek-gamaleldin. ibrahim.1@ens.etsmtl.ca inhomogeneity, short temporal coverage, sparse spatial coverage, and the inability to adequately represent the climate variability in all topographic and climatic zones, the stations are still considered to constitute the most accurate source of climate data (Tapiador et al. 2012; Nicholson 2013; Colston et al. 2018). In recent decades, to overcome some of the limitations of station data, several global and regional gridded datasets have been developed with different input data sources (gauges, radar, satellite, reanalysis, or combinations thereof), spatial resolutions $\left(0.05^{\circ}-2.5^{\circ}\right)$, spatial coverage (from continental to global), temporal scales (from $30 \mathrm{~min}$ to annual), and temporal coverage (from one to several years) (Henn et al. 2018). Such gridded datasets provide continuous spatial and temporal coverage, and typically, with no missing data.

Gridded datasets can be classified as a function of their data source. Gauge-based gridded datasets are obtained by interpolating and mapping the information measured at a small scale (typically, a point measurement at a weather station) onto a predefined spatial and temporal resolution grid. However, variations in gauge types or instrument replacements affect error characteristics in long-term records. In addition, observations are affected by systematic biases due to evaporation and wind effects, as well as the elevation of gauges in mountainous regions (Isotta et al. 2014). Gauges are also typically placed in regions allowing easier access for station maintenance and troubleshooting, meaning that the gauges do not necessarily reflect the actual climatic conditions of their surroundings. Interpolated station gridded climate data products are thus subject to these limitations and many integrate 
adiabatic lapse rates and elevation/precipitation relationships using terrain elevations in a bid to correct some of these shortcomings.

A different approach to measuring precipitation uses ground weather radars, as they partially address the issue of rain gauge spatial coverage since each radar site covers a relatively large area. However, radar coverage here is limited to high population developed regions. In addition, they provide estimates of the rainfall rate at certain observational levels above the ground and cannot detect surface precipitation. Therefore, the presence of weather stations is required for the calibration and correction processes between surface measurements and atmospheric precipitation estimates (Martens et al. 2013).

Nowadays, satellite products are available at the global scale, and can cover large areas at high spatial and temporal resolutions with near-real-time coverage. They are mainly suitable for rainfall estimation in the tropics and data-scarce regions. Given this advantage, satellite products have been used in water resource management studies (Giardino et al. 2010; Nishat and Rahman 2009; Siddique-E-Akbor et al. 2014), hydroclimatological studies (Khan et al. 2011; Jutla et al. 2015) and in extreme event analysis (Lockhoff et al. 2014; Boers et al. 2015). However, satellites are relatively insensitive and generally miss a significant quantity of light precipitation and tend to fail over snow- and ice-covered surfaces (Tian et al. 2009). Some studies have evaluated the uncertainties of these datasets and shown that high-resolution satellite products perform better when bias is corrected using gauge observations (Awange et al. 2016).

Retrospective analysis/reanalysis systems represent vital sources of data in weather and climate studies. A typical reanalysis system consists of two main components: the forecast model and the data assimilation system. The role of the data assimilation system is to integrate many sources of observations to provide the forecast model with the most accurate representation of initial atmospheric states. Then, the numerical weather forecast models are executed for a given time step to produce consistent gridded datasets (Di Luzio et al. 2008). Although reanalysis are not direct observations, they nevertheless provide analyzed variables, even in areas with minimal or nonexistent stations (Bosilovich 2013).

Overall, no single precipitation product could be considered ideal for measuring precipitation. In fact, all precipitation products tend to miss a significant volume of rainfall (Behrangi et al. 2011).

Near-surface air temperature is a key variable for meteorological monitoring and forecasting services (Nieto et al. 2011), as well as for climate and hydrological studies. In hydrological modeling, the air temperature is the main driving variable for the evapotranspiration and snowmelt processes. Hence, accurate temperature data are vital when driving hydrological models in historical and future climate periods. However, the lack of an adequate gauge network can result in improper temperature estimations. Therefore, gridded temperature datasets are also crucial in many fields. Temperature products are generally thought to be less complex than precipitation datasets due to the much smaller spatial and temporal temperature variability in the former. Therefore, significantly fewer studies have compared and evaluated the uncertainty of using different temperature datasets in hydrological impact models.

Appropriate dataset selection is a key issue in climate studies. High uncertainty is found across most gridded datasets, coming from multiple sources, such as using different data sources, merging and interpolation algorithms, or quality control techniques (Vogel 2013; Prakash et al. 2015a,b; Prein and Gobiet 2017; Nashwan et al. 2019). Moreover, the number and the accuracy of observations used to correct these products typically vary. However, some products are calibrated to the observations, thus making annual biases minimal, while their daily patterns are significantly different from the observations (Sylla et al. 2013). Therefore, gridded datasets should be comprehensively evaluated before they are used.

Several studies have assessed the performance, advantages and limitations of gridded datasets. Most of these studies focus solely on precipitation datasets and evaluate the accuracy of these products through a straightforward comparison against ground weather stations (Vila et al. 2009; Romilly and Gebremichael 2011; Jiang et al. 2012; Prakash et al. 2018; Nashwan et al. 2019). Andermann et al. (2011) evaluated five remote sensing and gauge-based gridded datasets with groundbased measurements in the Himalayan region. The results showed that the satellite products underestimate the precipitation at both the annual and seasonal scales. The authors reported that the findings likely resulted from the bias correction techniques applied to correct the datasets using the Global Telecommunication System (GTS) rain gauge network, which has a poor spatial coverage in the study region; in addition, $0 \mathrm{~mm}$ of precipitation is used to compensate for missing values in the database. Moreover, there is a lag experienced by the remote sensors in precisely capturing the snowfall, which is the major contributor of precipitation in the Himalayas. The conclusion that satellite approaches tend to fail in snowdominant regions has also been reported in other studies (Kidd et al. 2012; Laviola et al. 2013). Chen et al. (2014) also evaluated two satellite-based products, CMORPH (Joyce et al. 2004) and PERSIANN-CCS (Ashouri et al. 2015), to capture the rainfall in the mountainous zones located west and north of Beijing. The study showed that both datasets failed to capture the spatial pattern and the temporal variation of precipitation.

Other studies have used hydrological modeling as an indirect method to evaluate the performance of these datasets in forcing hydrological models (Zhu et al. 2018; Duan et al. 2019; Tarek et al. 2020). Hydrological modeling offers an interesting perspective since results depend on the coherence between precipitation and temperature datasets and on an accurate representation of the annual cycle of both variables. Hydrological modeling is also not overly sensitive to biases present in every dataset, as these are typically removed during the calibration process (Essou et al. 2016). Behrangi et al. (2011) evaluated five satellite-based products to force a hydrological model and simulate streamflows. The results showed that the bias-corrected datasets captured streamflow patterns well. However, the non-bias-corrected products overestimated the streamflow over warm seasons and underestimated it in cold seasons. Wu et al. (2018) evaluated the Multi-Source 


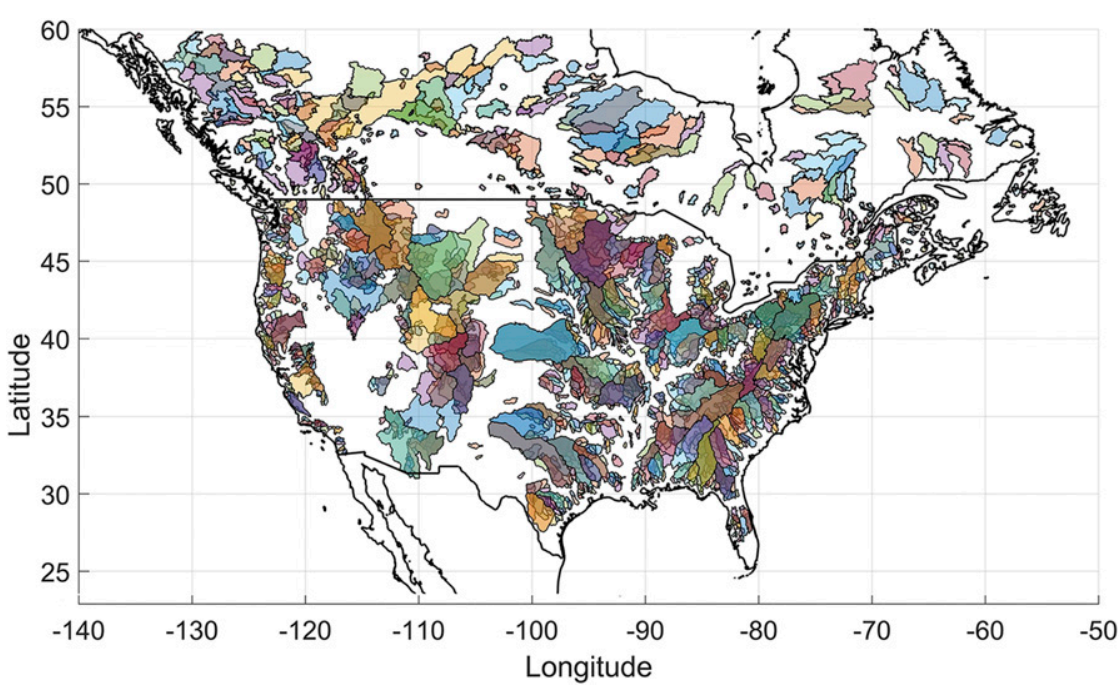

FIG. 1. Spatial distribution of the 3138 North American basins.

Weighted-Ensemble Precipitation (MSWEP V2.1) and three satellite-based precipitation products with rain gauge observations to simulate streamflows on the upper Huaihe River basin in China. The results showed that the merged precipitation product (MSWEP) generally outperformed the other satellite datasets, although significant uncertainty existed in mountainous regions. Beck et al. (2017b) evaluated 23 gridded precipitation datasets over the $2000-16$ period. Thirteen daily uncorrected datasets (nondependent on gauges for correction) were compared with observations from gauges, and the other 10 gauge-corrected datasets were evaluated using hydrological modeling. Among the uncorrected datasets, the mergedproducts datasets (MSWEP-ng) generally performed the best, followed by the reanalysis and then the satellite products. For the corrected datasets, results showed that datasets integrating daily gauge data (CPC Unified and MSWEP products) generally outperformed the other datasets. Finally, precipitation datasets have also been evaluated using the surface water budget (Getirana et al. 2011; Lorenz et al. 2014; Munier and Aires 2018; Sheffield et al. 2009; Smith and Kummerow 2013; Song et al. 2016), as well as using surface water and energy budgets (Kang and Ahn 2015; Hobeichi et al. 2020a,b; Yang et al. 2015).

Despite the growing literature on the subject, the question regarding the most accurate dataset for capturing the spatiotemporal variability of weather events or driving hydrological models for climate change impact studies remains unanswered. The main objective of this study is therefore to establish a large-scale comparison of available temperature and precipitation datasets covering a time period long enough to define the regional climate and therefore having the potential to be used as reference datasets to bias-correct climate model outputs for climate change impact studies. Secondary objectives include a comparison of families of climate data sources (gauges, gridded products, satellite products, and reanalysis products), a quantification of the variability between the different datasets, and providing recommendations on their applicability depending on the region of interest and physiographic characteristics.

\section{Study region and data}

\section{a. Study region}

The study region is composed of 3138 catchments distributed over North America. The catchments were selected from the NAC2H (North American Climate Change and Hydroclimatology) database (Arsenault et al. 2020), which is a set of preprocessed catchments for climate change studies that is a subset of the larger HYSETS (Hydrometeorological Sandbox-École de technologie supérieure) database (Arsenault et al. 2020). Figure 1 presents the geographic distribution of the catchments, and Table 1 presents the main statistics of the set of catchments.

\section{b. Data}

\section{1) GRIDDED PRECIPITATION AND TEMPERATURE DATASETS}

Currently, a significant number of gridded datasets have been stockpiled from stations, satellites, reanalyses, or a combination thereof. However, not all these datasets can be used for climate change impact studies. To be useful, a dataset must have the following characteristics: 1) spatial resolution (finer than $1^{\circ}$ for example to be used in local hydrological studies); 2) daily scale or finer temporal resolution; 3) long temporal coverage (at least 30 years to establish robust statistics for downscaling and bias correction); and 4) for an intercomparison study, all datasets should cover approximately the same time period.

Based on these criteria, nine precipitation and three temperature gridded datasets are included in this study, and are presented in (Table 2). The precipitation datasets are classified based on their respective data sources. Two datasets are based solely on gauge data: CPC Unified (Climate Prediction Center 
TABLE 1. Main properties of the study basins.

\begin{tabular}{|c|c|c|c|c|}
\hline Basin attribute & Minimum & Maximum & Median & Mean \\
\hline Elevation (m) & 7.3 & 3585 & 380 & 692 \\
\hline Area $\left(\mathrm{km}^{2}\right)$ & 302 & 179150 & 1803 & 6317 \\
\hline Mean annual precipitation $\left(\mathrm{mm} \mathrm{yr}^{-1}\right)$ & 307 & 3895 & 993 & 981 \\
\hline Mean annual discharge $\left(\mathrm{m}^{3} \mathrm{~s}^{-1}\right)$ & 0.048 & 1584 & 17.60 & 56.75 \\
\hline Temporal coverage within the study period (years) & 3 & 30 & 30 & 27.6 \\
\hline
\end{tabular}

Unified Gauge) and GPCC (Global Precipitation Climatology Center); two combine gauge and satellite data: CHIRPS V2.0 (Climate Hazards Group Infrared Precipitation with Stations) and PERSIANN-CDR V1R1 [Precipitation Estimation from Remotely Sensed Information using Artificial Neural Networks (PERSIANN) Climate Data Record (CDR)]; four are derived from reanalysis: ERA5 [European Centre for Medium-Range Weather Forecasts (ECMWF) fifth generation reanalysis], ERA-Interim (ECMWF interim reanalysis), JRA55 (Japanese 55-year Reanalysis), and NCEP CFSR (National Centers for Environmental Prediction Climate Forecast System Reanalysis), while the last is a multisource dataset integrating gauge, satellite and reanalysis data (MSWEP V1.2). In terms of temperature, three datasets are included in this study: the gauge-based CPC Unified dataset the ERAInterim and ERA5 reanalysis products. Properties of the temperature datasets are also provided in Table 2.

There are additional satellite products that provide global rainfall information at finer resolutions than PERSIANNCDR, which has been selected in this work. Of particular interest is the Global Precipitation Measurement (GPM) mission, designed to further precipitation monitoring from an array of microwave sensors. It was launched to provide a new generation of precipitation datasets with an improved accurate measurement for light rainfall and snow precipitation as well as more frequent observations over the medium and high latitudes (Hou et al. 2014). GPM utilizes passive microwave sensors in addition to the infrared measurements from geostationary satellites, providing rainfall monitoring around the globe with higher spatial and temporal resolutions than the previously widely used TMPA products (Yong et al. 2015). These improvements are likely to provide significant advantages for hydrometeorological studies, weather forecasting, water budget studies, and many other applications. In particular, the GPM Integrated Multisatellite Retrievals (IMERG), provides data at $0.1^{\circ}$ and half-hourly spatial and temporal scales (Huffman et al. 2015) and the Global Satellite Mapping of Precipitation (GSMaP) provides hourly rainfall data also at a $0.1^{\circ}$ resolution (Okamoto et al. 2005). These products have been evaluated against gauge measurements over different regions (Aslami et al. 2019; Asong et al. 2017; Chen et al. 2016; Lu and Yong 2018; Mazzoglio et al. 2019) and showed satisfactory results. However, these state-of-the-art products do not cover a long-enough time period to be used for the evaluation of a climatic baseline period required for climate change impact studies. They were therefore not chosen for this study.

\section{2) OBSERVED HYDROMETEOROLOGICAL DATA}

The observed data (OBS) in this study were taken from the $\mathrm{NAC} 2 \mathrm{H}$ database, which is a hydrology and climate change impact dataset developed to study the impacts of different components of the modeling chain on hydrological indices over a collection of 3540 North American catchments. It includes hydrometeorological data such as precipitation,

TABLE 2. Selected global gridded datasets.

\begin{tabular}{|c|c|c|c|c|c|c|c|}
\hline & Short name & Data source & $\begin{array}{l}\text { Spatial } \\
\text { resolution }\end{array}$ & $\begin{array}{l}\text { Spatial } \\
\text { coverage }\end{array}$ & $\begin{array}{l}\text { Temporal } \\
\text { resolution }\end{array}$ & $\begin{array}{l}\text { Temporal } \\
\text { coverage }\end{array}$ & Reference \\
\hline \multicolumn{8}{|c|}{ Precipitation } \\
\hline 1 & CPC Unified & Gauge & $0.5^{\circ}$ & Global & Daily & 1979-present & Chen et al. (2008) \\
\hline 2 & GPCC & Gauge & $1.0^{\circ}$ & Global & Daily & 1982-2016 & Schneider et al. (2014) \\
\hline 3 & PERSIANN-CDR V1R1 & Gauge, satellite & $0.25^{\circ}$ & $\pm 60^{\circ}$ lat & 6 hourly & 1983-2012 & Ashouri et al. (2015) \\
\hline 4 & CHIRPS V2.0 & Gauge, satellite & $0.05^{\circ}$ & $\pm 50^{\circ}$ lat & Daily & 1981-present & Funk et al. (2015) \\
\hline 5 & NCEP CFSR & Reanalysis & $0.5^{\circ}$ & Global & 6 hourly & 1979-2012 & Saha et al. (2010) \\
\hline 6 & ERA-Interim & Reanalysis & $0.75^{\circ}$ & Global & 3 hourly & 1979-August 2019 & Dee et al. (2011) \\
\hline 7 & ERA5 & Reanalysis & $0.25^{\circ}$ & Global & Hourly & 1979-2017 & $\begin{array}{l}\text { Hersbach and Dee } \\
\text { (2016) }\end{array}$ \\
\hline 8 & JRA-55 & Reanalysis & $0.5625^{\circ}$ & Global & 3 hourly & 1959-present & $\begin{array}{l}\text { Kobayashi et al. } \\
\quad(2015)\end{array}$ \\
\hline 9 & MSWEP V1.2 & Gauge, satellite, reanalysis & $0.25^{\circ}$ & Global & 3 hourly & 1979-2015 & Beck et al. (2017a) \\
\hline \multicolumn{8}{|c|}{ Temperature } \\
\hline 1 & CPC Unified & Gauge & $0.5^{\circ}$ & Global & Daily & 1979-present & Chen et al. (2008) \\
\hline & ERA-Interim & Reanalysis & $0.75^{\circ}$ & Global & 3 hourly & 1979-August 2019 & Dee et al. (2011) \\
\hline 3 & ERA5 & Reanalysis & $0.25^{\circ}$ & Global & Hourly & 1979-2017 & $\begin{array}{l}\text { Hersbach and Dee } \\
\quad(2016)\end{array}$ \\
\hline
\end{tabular}


maximum and minimum temperature, and streamflow at the daily scale for each of the catchments. Observed meteorological data come from regional datasets interpolated from station data. For Canada, the data are sourced from Environment and Climate Change Canada (ECCC), whereas Canadian streamflow data are provided by Water Survey Canada, the hydrometric branch of ECCC. In the United States, NAC2H uses the Livneh gridded dataset for meteorological data, whereas streamflows are provided by the United States Geological Survey (USGS) National Water Information Service. NAC2H data are open source and available on the Open Science Foundation data repository (https://osf.io/s97cd/). More details can be found in Arsenault et al. (2020).

\section{Methodology}

\section{a. Intercomparison of gridded climate products} and statistics

The first step in this study was to evaluate the different products relative to a reference dataset-in this case, the $\mathrm{NAC} 2 \mathrm{H}$ observation dataset. While it was considered as the reference dataset, there was no underlying assumption that it is of higher quality or more accurate than any of the gridded products. Rather, it simply served as a baseline against which the other data products were compared. Analyses were performed by comparing annual and seasonal means of the gridded climate variables to the reference. This allowed finding spatial patterns of differences in average precipitation and temperatures to obtain a first feeling on the regional differences between the products. Then, a similar analysis was performed to investigate the differences in variability within these datasets on a daily time step. This also allowed evaluating the properties at a time scale that is more difficult to manage for gridded datasets than are aggregated annual or seasonal scales. The tests were performed because gridded datasets presenting no annual differences in precipitation versus the reference could still be largely underestimating the variance found in observational records. Metrics such as the mean error (ME), mean absolute error (MAE), root-mean-square error (RMSE), and correlation coefficient $(r)$ were used to compare the annual and seasonal precipitation and temperature values to the reference datasets, allowing to quantify the level of departure from the reference data.

\section{b. Evaluation using hydrological modeling}

The quality and performance of the climate variable datasets were evaluated indirectly through an independent measure, namely, the watershed observed streamflow. The hypothesis posed here is that climate datasets that allow for more accurate hydrological modeling with respect to the observed streamflow should be considered as being of higher quality. Of course, the choice of a hydrological model does influence performance. However, this should be seen as a first attempt at finding inconsistencies within the climate datasets. Hydrological modeling is sensitive to the annual cycle of precipitation and temperature, as well as to the coherency between both variables, so it can therefore be seen as a good evaluator of dataset overall quality.
This approach has been used in several other studies (e.g., Beck et al. 2017b; Essou et al. 2016; Tarek et al. 2020).

\section{1) HMETS}

HMETS (Hydrological Model-École de technologie supérieure) is a lumped and conceptual model used in many research applications and as a component of operational multimodel hydrological studies and forecasting (Martel et al. 2017). It was selected due to its good performance in the study domain in previous studies and because a lumped model was required to simulate discharge over the large number of catchments in the study.

HMETS is a 21-parameter, reservoir-based model that simulates water balance, including snow processes and the horizontal hydrological fluxes, using a series of unit hydrographs. It requires daily maximum and minimum temperature as well as daily rainfall and snowfall amounts. All the chosen temperature datasets provide daily minimum and maximum temperature, with the exception of ERA5, which provides mean hourly air temperature. The minimum and maximum hourly temperatures for each day were therefore used as being representative of the daily maximum and minimum values. When needed by the hydrological model, mean daily temperature was computed as the average of daily minimum and maximum temperatures. HMETS starts by computing the potential evapotranspiration using the Oudin formulation (Oudin et al. 2005), which is scaled through a calibration parameter, and then computes snow accumulation and melt with a 10-parameter degree-day-based snow module developed by Vehviläinen (1992). Rainfall is then added to the runoff generated by snowmelt to obtain total water production. Potential evapotranspiration is then subtracted from the total water production to obtain the final runoff depths. The water then infiltrates into one of three underground soil layers modeled as reservoirs (the aquifer, the vadose zone, and the delayed surface runoff zone), using six calibrated parameters. Some of the water is also kept above the soil as the surface runoff reservoir. Water from these reservoirs is routed using two independent two-parameter gamma distribution unit hydrographs for the surface unit hydrograph and the delayed unit hydrograph, respectively.

\section{2) HYDROLOGICAL MODEL CALIBRATION}

HMETS was calibrated using the automatic Covariance Matrix Adaptation Evolution Strategy (CMAES) optimization algorithm (Hansen et al. 2003), which was shown to perform well with such optimization problems (Arsenault et al. 2014). The objective function used to calibrate the parameters was the Kling-Gupta efficiency (KGE) metric, which was introduced by Gupta et al. (2009) and modified by Kling et al. (2012), and which is an equally weighted bias, variance, and correlation aggregate metric. It has been shown to be more easily interpreted than the Nash-Sutcliffe efficiency (Nash and Sutcliffe 1970) metric from which it is derived. The KGE values theoretically range from negative infinity (extremely poor performance) all the way to one (perfect performance). The performance ratings used in this study are defined based on the work of Gutenson et al. (2020) and Pechlivanidis and 

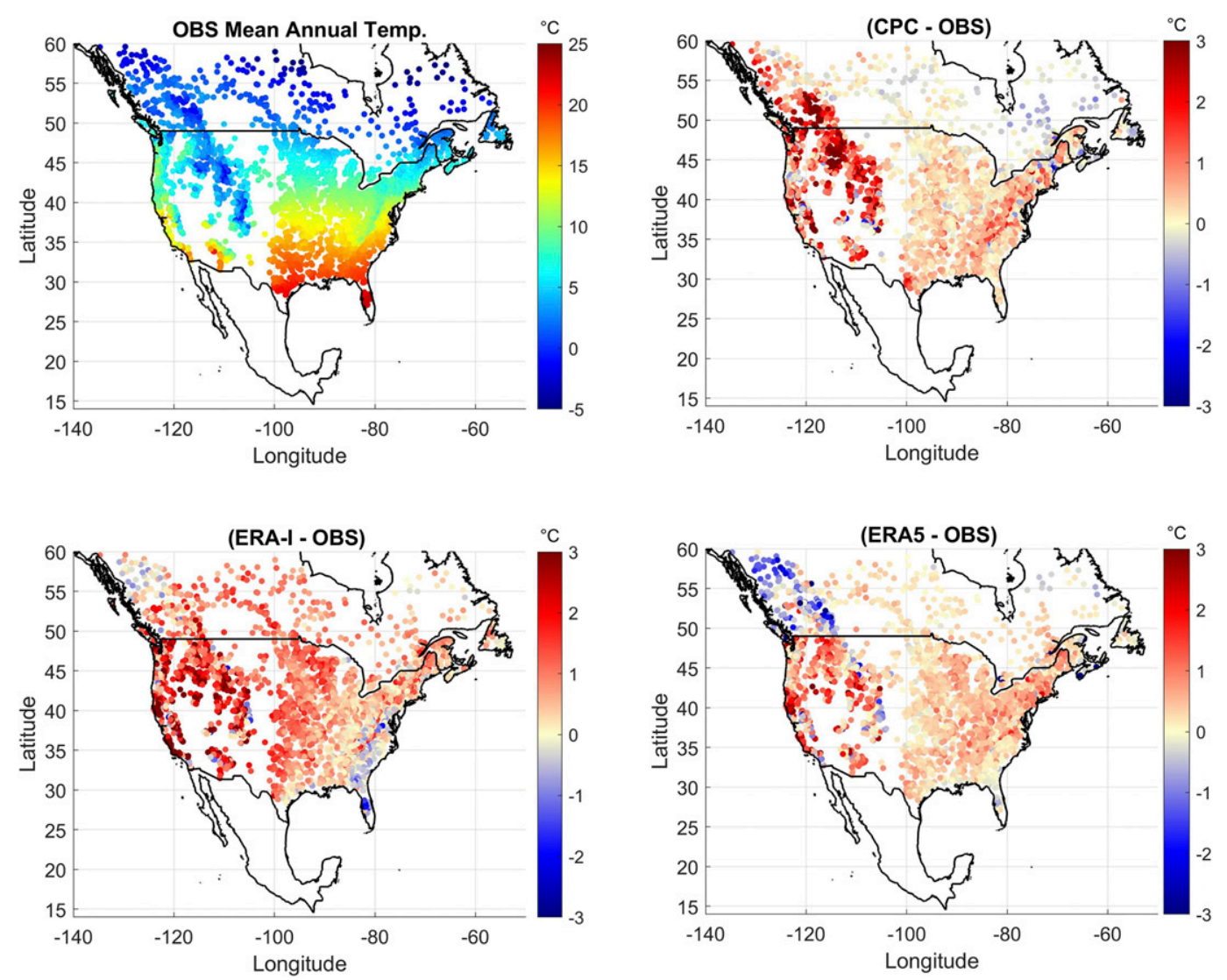

FIG. 2. Difference maps for the mean annual temperature (dataset - OBS) for the period (1983-2012).

Arheimer (2015), who divide KGE values into three modelingperformance groups: poor performance $(\mathrm{KGE}<0.4)$, acceptable $(0.4 \leq \mathrm{KGE}<0.7)$, and good $(\mathrm{KGE} \geq 0.7)$. Both precipitation and temperature datasets were averaged at the catchment scale before being fed to the hydrological model. Each catchment was calibrated by letting CMAES converge over 15000 model evaluations and repeating the process twice. The calibration was performed on the entire length of the available data as recommended in (Arsenault et al. 2018). The best calibration KGE score from the two generated sets was used to reduce the chance of considering a parameter set that had not properly converged to an acceptable minimum. This calibration procedure was repeated for each combination of precipitation and temperature datasets, including the reference datasets, for each watershed, in order to allow their objective comparison (Essou et al. 2016).

\section{Results}

The results of the climatic variables analysis are first presented, followed by an analysis of the performance of the precipitation and temperature data when used in hydrological modeling.

\section{a. Analysis of precipitation and temperature}

Figure 2 shows the average daily temperature of the reference dataset (upper left) and differences between each of the three chosen temperature datasets. The term difference is used below, instead of bias, since our reference dataset is not a true representation of the population and is not inherently better than other datasets.

On average, the three datasets are warmer than the observations, with ERA-Interim being the warmest. The warm difference is particularly clear in the western United States. Overall, ERA5 is the closest to observations, with small differences across central and eastern North America, and reduced differences on the west coast. Figure 3 presents a similar analysis for precipitation. It shows observed mean annual precipitation (upper left) and differences of the nine studied precipitation datasets.

It can be seen in Fig. 3 that the precipitation products differ widely, depending on the source and type of processing of data. Datasets that integrate observations (CPC, GPCC, and MSWEP in the top row and PERSIANN and CHIRPS in the bottom row) show much smaller differences in general, as compared to the four reanalysis products (middle row). ERA5 is the bestperforming reanalysis, followed by its predecessors, ERAInterim, JRA55, and CFSR products, which are wetter over most of North America. Figure 3 also shows large differences in the western mountain ranges for all datasets, outlining limitations for all gridded precipitation datasets under study.

To further investigate precipitation seasonality, Figs. 4 and 5 present seasonal precipitation differences for winter (DJF) and summer (JJA). 

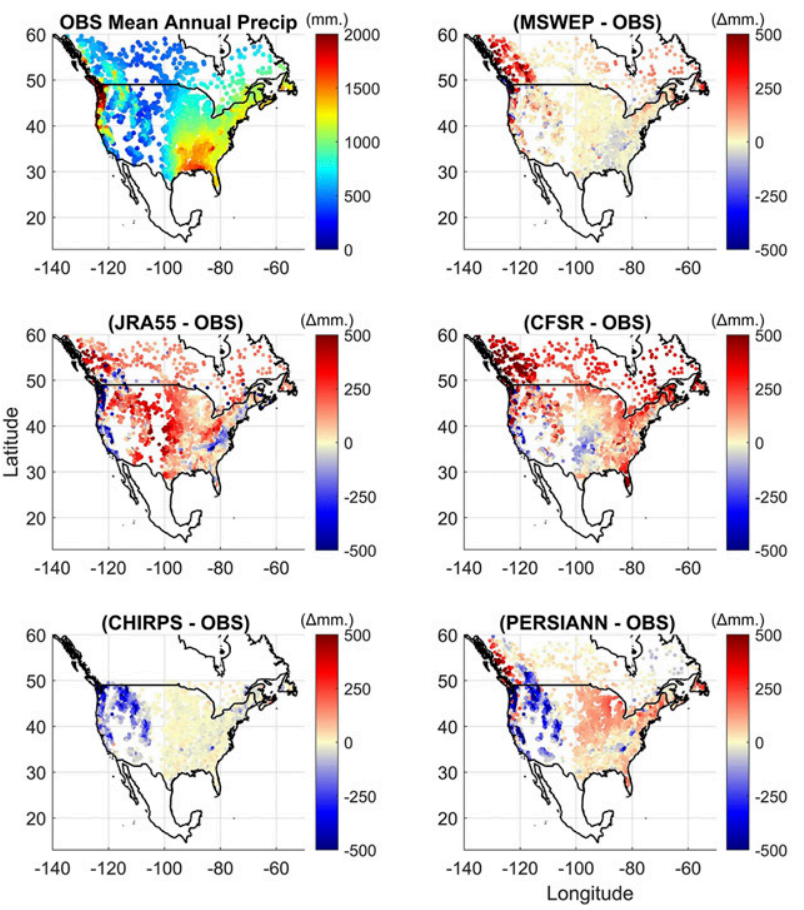

Results for winter are very similar to those obtained at the annual scale. Summer differences (Fig. 5) do, however, display important differences. These differences are smaller for the satellite-based datasets and larger for the reanalysis datasets in general. The CFSR reanalysis is particularly dry in central USA. The differences between ERA5 and ERA-Interim are also larger, with ERA5 having smaller differences all across North America.

To analyze the results at a more localized scale, mean annual precipitation statistics were computed for each catchment and compared to the reference precipitation dataset. Figure 6 presents boxplots for annual precipitation ME, MAE, RMSE and correlation coefficient. The spatial distribution of the last two metrics is also presented in Figs. 7 and 8 . The boxplots are built from 3138 values, one from each individual catchment. The central boxes show the 25 th and 75 th quantiles (bottom and top), with the median in red. The whiskers display the smallest and largest values. Red crosses are considered statistical outliers. Overall, when compared to the reference dataset, we see that MSWEP is consistently the closest across all metrics. The two gauge-based products (CPC and GPCC) and CHIRPS follow. The median difference of ERA-Interim is close to zero, but otherwise displays a large spread. Surprisingly, ERA5 shows a relatively large positive mean difference, as do the other reanalyses (JRA55, CFSR). Correlation coefficients tell a similar story, with the main differences being that ERA5 clearly outperforms the other reanalysis. RMSE distributions also follow a similar pattern.

Figure 7 presents the spatial distribution of mean annual precipitation RMSE values between each precipitation dataset and observations. JRA55 and CFSR are clearly the
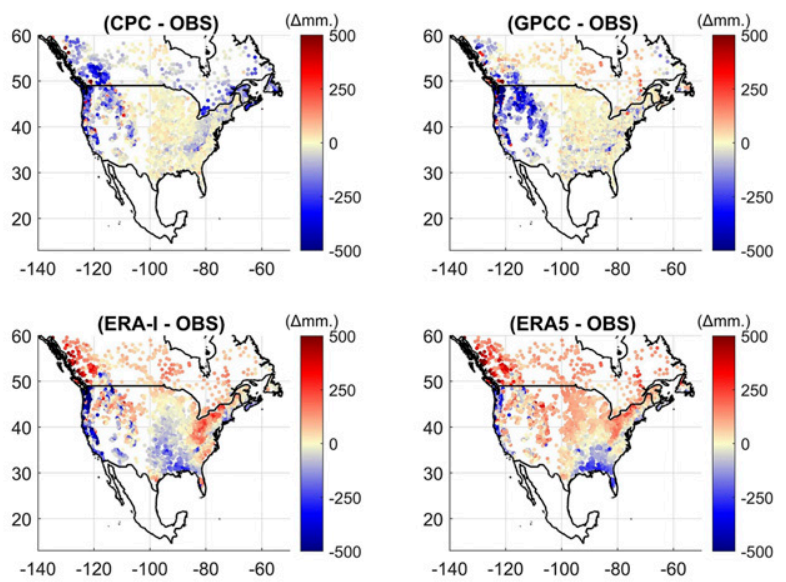

FIG. 3. Difference maps for mean annual precipitation (dataset - OBS). Note that CHIRPS does not provide data beyond $\pm 50^{\circ}$ latitude. worst-performing datasets. MSWEP performs the best everywhere, with the exception of western Canada, where ERA-5 and GPCC perform best. Figure 8 presents the spatial distribution of correlation coefficients calculated for daily precipitation. MSWEP, ERA5, GPCC, and CHIRPS are clearly the best-performing datasets. CPC performs well over the United States, but quite badly in Canada, where weather station density gets lower.

To investigate in more details, the distribution of precipitation amounts at the watershed scale was examined. Figure 9 presents quantile-quantile plots for the Saint Louis River watershed. This catchment was chosen as its behavior is typical of most other watersheds, even though there is some level of regional control on quantile biases (not shown). The median quantile is represented by the solid red circle on each graph. This figure therefore emphasizes the larger quantiles. The most striking feature of Fig. 9 is the overestimation of the larger quantiles at the catchment level for most datasets. This is particularly the case for all reanalyses, CHIRPS, and GPCC. The lower quantiles are generally well represented by all datasets.

\section{b. Hydrological model simulations}

This section presents the results of the hydrological model simulations using all possible combinations of precipitation and temperature datasets. Figures 10 and 11 show the distributions of KGE scores for all catchments below (Fig. 10) and above $50^{\circ} \mathrm{N}$ (Fig. 11). The separation at $50^{\circ} \mathrm{N}$ was made for two reasons: the unavailability of data for CHIRPS, and to investigate the impact of the much lower resolution of observation networks in the north, which should technically affect gauge-based datasets. 

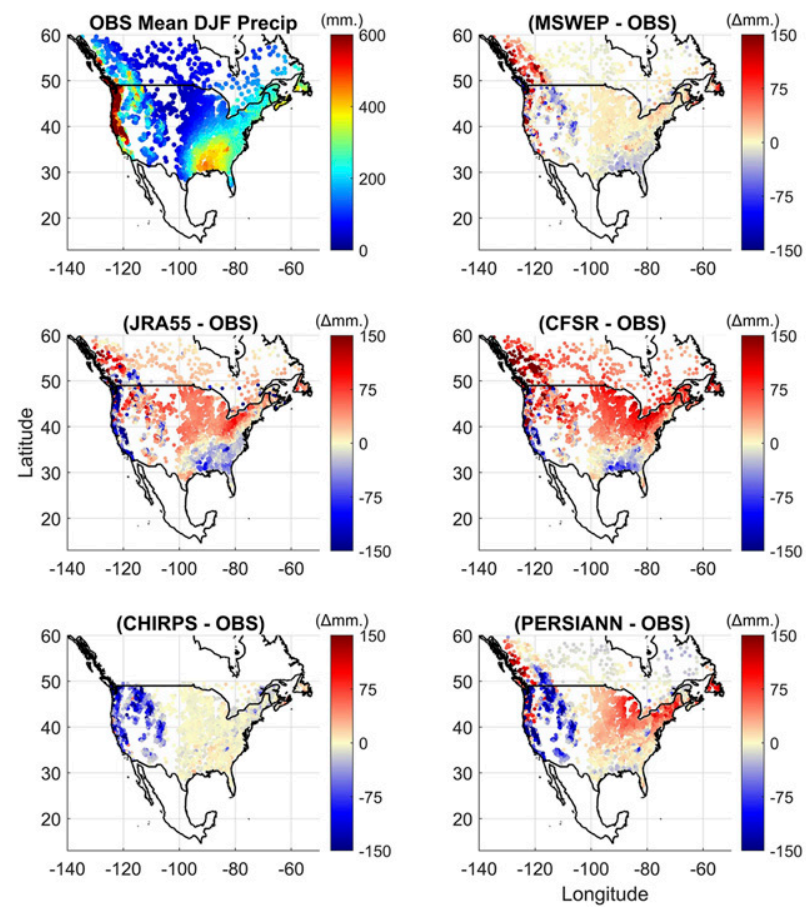

Figure 10 shows that all datasets can be used to generate good hydrological modeling, with all combinations generating median KGE values larger than 0.7 . There are, however, large performance variations across datasets. The main driver of the modeling skill is the precipitation dataset. All four temperature datasets offer a nearly equal performance below $50^{\circ} \mathrm{N}$, although CPC is consistently the worst
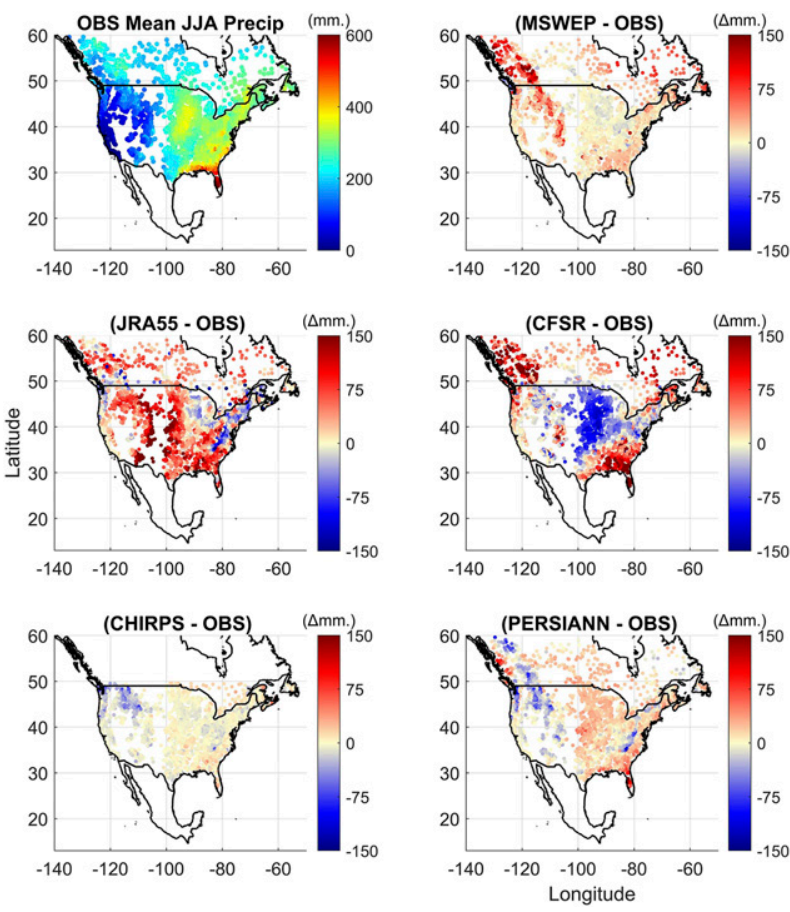
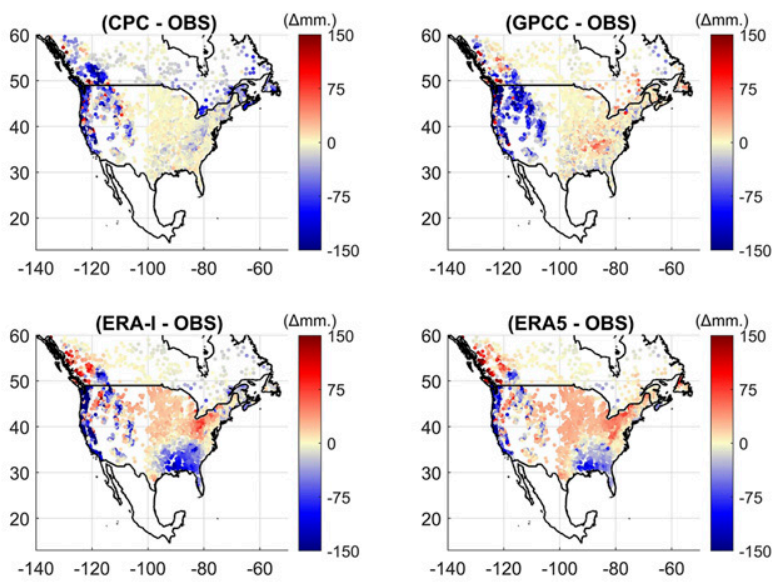

FIG. 4. Mean winter (DJF) precipitation difference maps for the 1983-2012 period.

of the four. The reference and MSWEP datasets clearly outperform all other precipitation datasets. These are then followed by the GPCC and CPC gauge-interpolated datasets, and then by CHIRPS and ERA5. The other satellite (PERSIANN) and reanalysis (ERA-Interim, JRA-55, and CFSR) products perform clearly worse than their best counterparts (CHIRPS and ERA5).
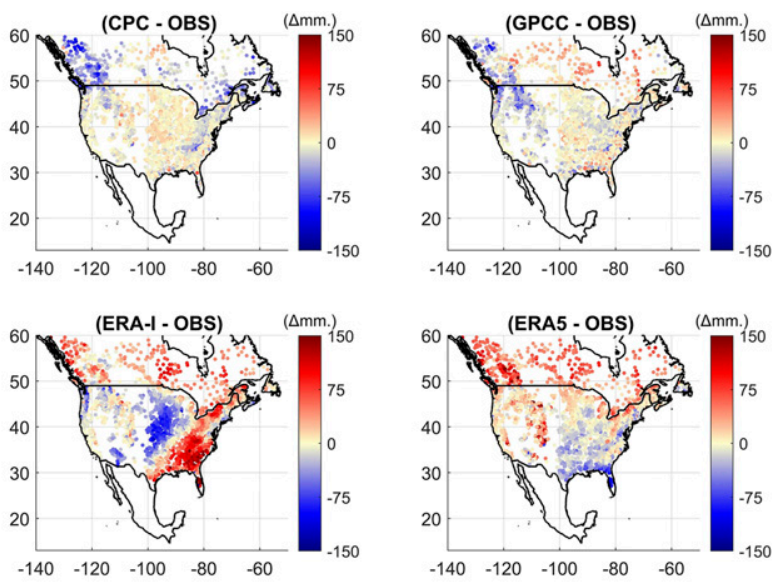

FIG. 5. Mean summer (JJA) precipitation difference maps for the 1983-2012 period. 

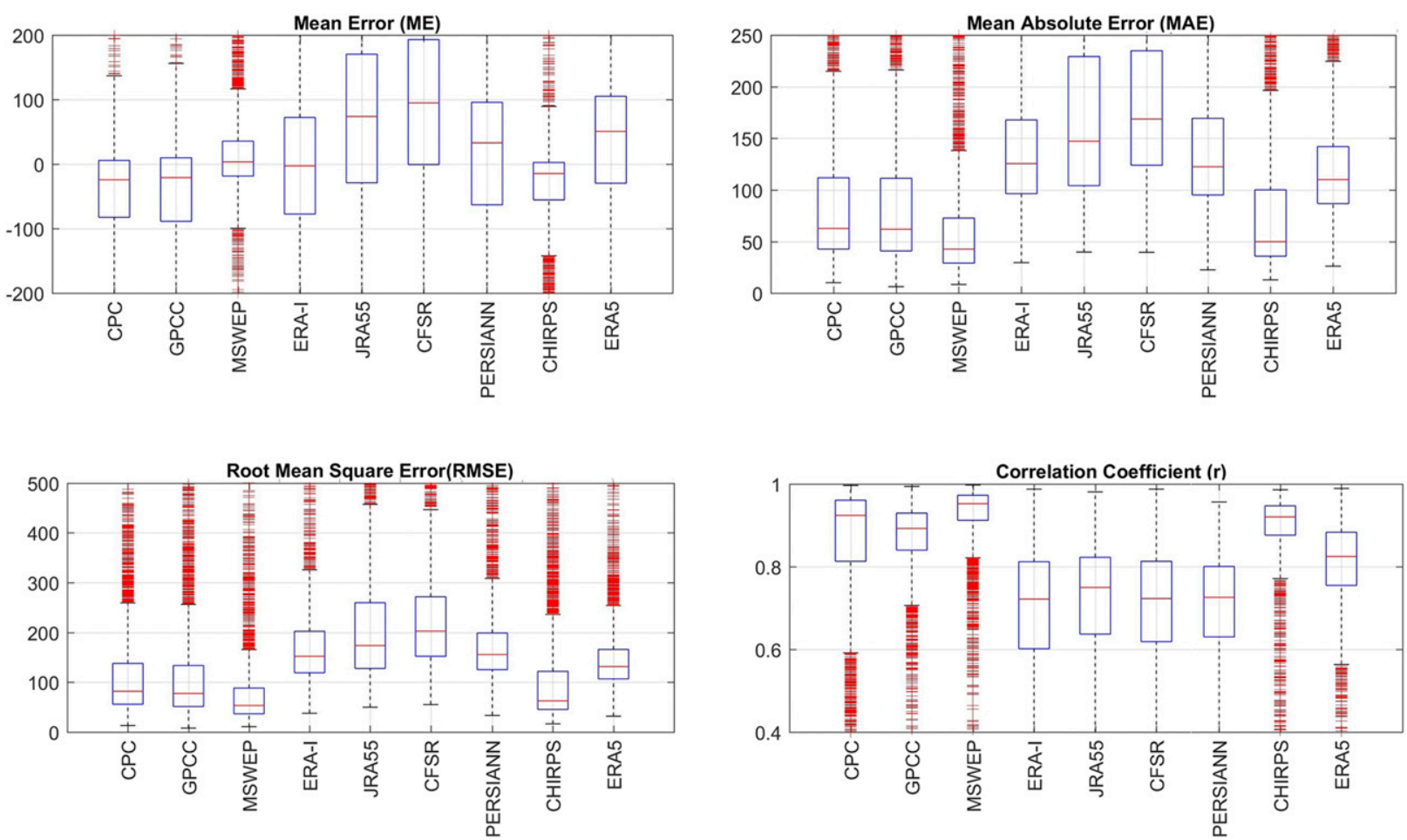

FIG. 6. Boxplots comparing ME, MAE, RMSE, and $r$ for nine precipitation datasets at the annual scale.

The results for catchments north of $50^{\circ} \mathrm{N}$ (Fig. 11) are markedly different. The differences between all datasets is much smaller, with the exception of CPC, which is the worstperforming dataset. This is consistent with results presented in Fig. 8 showing that CPC precipitation behaves quite differently over Canada. The lower density of the station network is an equalizer, preventing gauge-based datasets from outperforming their counterparts. MSWEP and ERA5 are the best-performing datasets, and are slightly better than using the regional gridded dataset used as a reference. Overall, hydrological modeling performance is very good, and, for most datasets, better than below $50^{\circ} \mathrm{N}$. This is very likely a combination of watersheds being larger, thus producing smoother, less reactive and easier to model hydrographs, and because snowdominated catchments typically have relatively simple hydrographs, with a long winter recession curve and a strong spring snowmelt signature. The gain in performance is notable for all reanalyses, which are less affected by a deficient local observational network.

Figure 12 shows the spatial distribution of KGE scores for the different precipitation datasets combined with the reference temperature dataset. The upper left graph shows the KGE values for the reference dataset, whereas all the other graphs display the difference in KGE values for each precipitation dataset. A red color indicates a better performance, and blue, a worse one. It can be seen that MSWEP, GPCC, and CHIRPS to some extent, compare favorably with the reference dataset, and that CPC is affected by the lack of stations in the northern parts of North America. Also of note is the strong negative score associated with some of the reanalysis and satellite datasets in the eastern United States. Outside of this zone, ERA5 performs extremely well, as noted by Tarek et al. (2020).

Finally, Fig. 13 presents the aggregate mean KGE score over all catchments for all precipitation-temperature pairs (first row), as well as for the catchment below (second row) and above $50^{\circ} \mathrm{N}$ (third row). The first two rows are nearly identical due to the much larger number of stations located below $50^{\circ} \mathrm{N}$. The third row displays warmer colors related to the prevalence of snowmelt-dominated watersheds, which are easier to model. Otherwise, these results confirm those of Fig. 12, and underline the relatively poor performance of CPC above $50^{\circ} \mathrm{N}$ for precipitation, and to a lesser extent, for temperature. Reanalysis datasets perform comparatively much better with both ECMWF reanalysis (ERA5 and ERA-Interim) products.

\section{Discussion}

Impact models strongly rely on hydrometeorological information. The performance of such models (stochastic and deterministic) is fundamentally dependent on the quality of input data. Weather station observations are considered as key information for most applications but are limited in both time and space. Time series of relevant hydrometeorological variables are plagued with problems such as short temporal horizons, missing data, measurement errors, instrument biases, and discontinuities introduced through equipment change and modification of the environment of weather stations, including their displacement. The low spatial density of stations in many parts of the world, as well as the slow but steady decreasing 

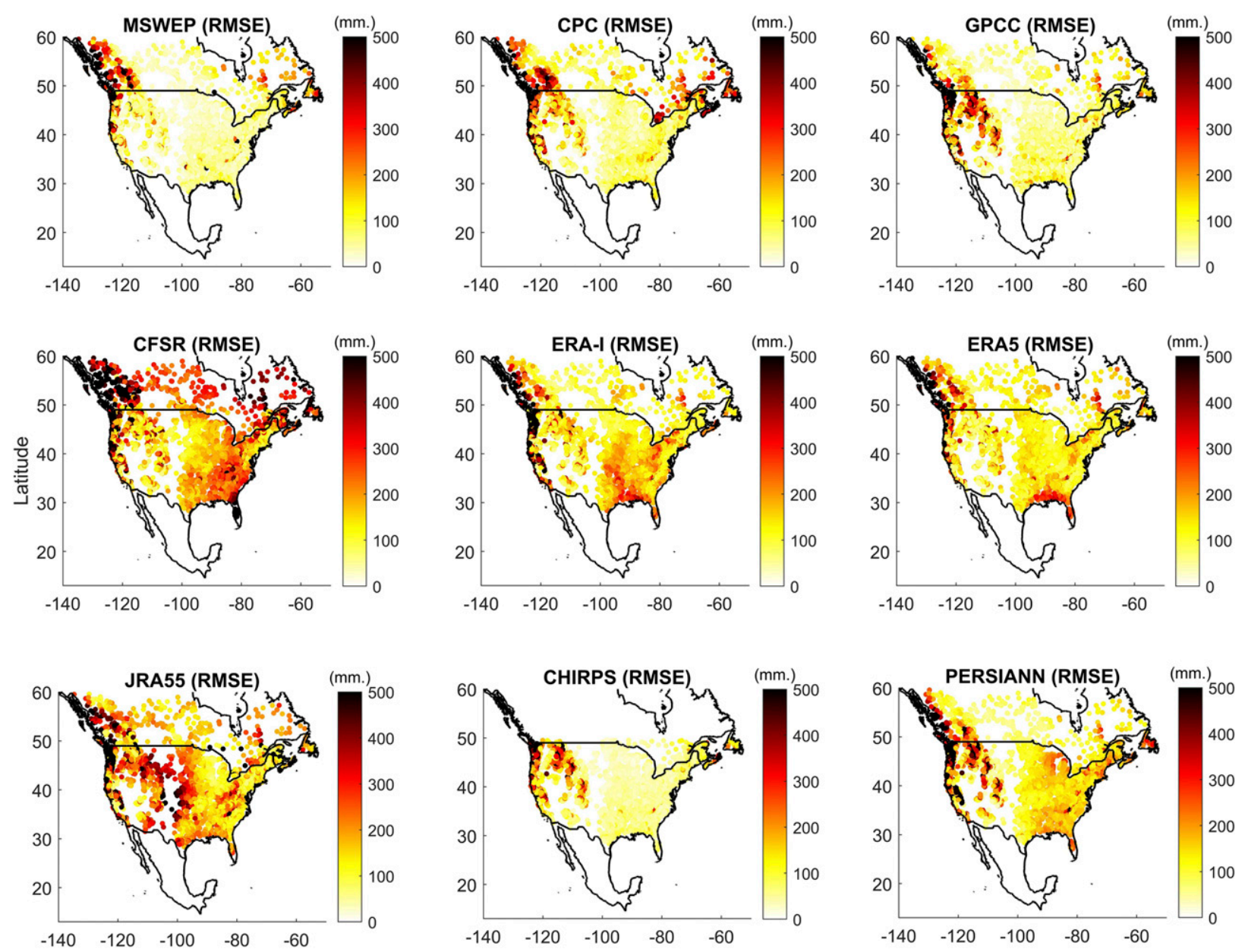

FIG. 7. RMSE of mean annual precipitation for nine precipitation datasets.

trend in the number of weather stations around the world (Lawrimore et al. 2011), compounds the problem. Gridded datasets are created to try to overcome many of the above problems. While it is likely that multisource merged gridded products are the way of the future, it is not clear how good and reliable the many currently available gridded products are. This paper sheds some light on this issue by comparing nine global or near-global precipitation datasets and three temperature datasets over North America, therefore combining regions with high and low densities of weather stations.

The results showed important differences between all the datasets, as well as within categories of datasets (gauge-based, reanalysis, and satellite-based). All the datasets were shown to be adequate for driving a hydrological model over 3138 catchments across North America. However, some datasets were clearly better than others in various circumstances. A first conclusion was that precipitation datasets are the main drivers of uncertainty. There was little difference between the four selected temperature datasets (NAC2H observations, CPC, ERA-Interim, and ERA5), even though CPC performed slightly worse than the selected reanalyses (ERA5 and ERA-Interim) and the reference gridded dataset. The equal performance of both reanalyses, when compared to the reference gridded datasets, could likely be explained by the fact that they assimilate the surface temperature from weather stations (in addition to a plethora of other data sources) and by the relatively small spatial and temporal variability of temperature, at least when compared to precipitation. Our evaluation of temperature is, however, based solely on hydrological modeling. Hydrological models have the ability to filter out some level of variability in driving inputs. Many other levels of validation still need to be performed (e.g., extremes) to determine if these alternative products are able to represent specific types of events in the hydrologic cycle. These results are nonetheless very encouraging for reanalyses, which are now available in near-real time and at spatial and temporal resolutions matching or exceeding those of most observational networks.

Comparatively, precipitation datasets provided a much more complex comparison picture. One important conclusion of this work is that the relative performance of precipitation datasets below $50^{\circ} \mathrm{N}$, which includes the contiguous United States and southern Canada, and above $50^{\circ} \mathrm{N}$. Above $50^{\circ} \mathrm{N}$, the density of the Canadian observational network is much lower. 

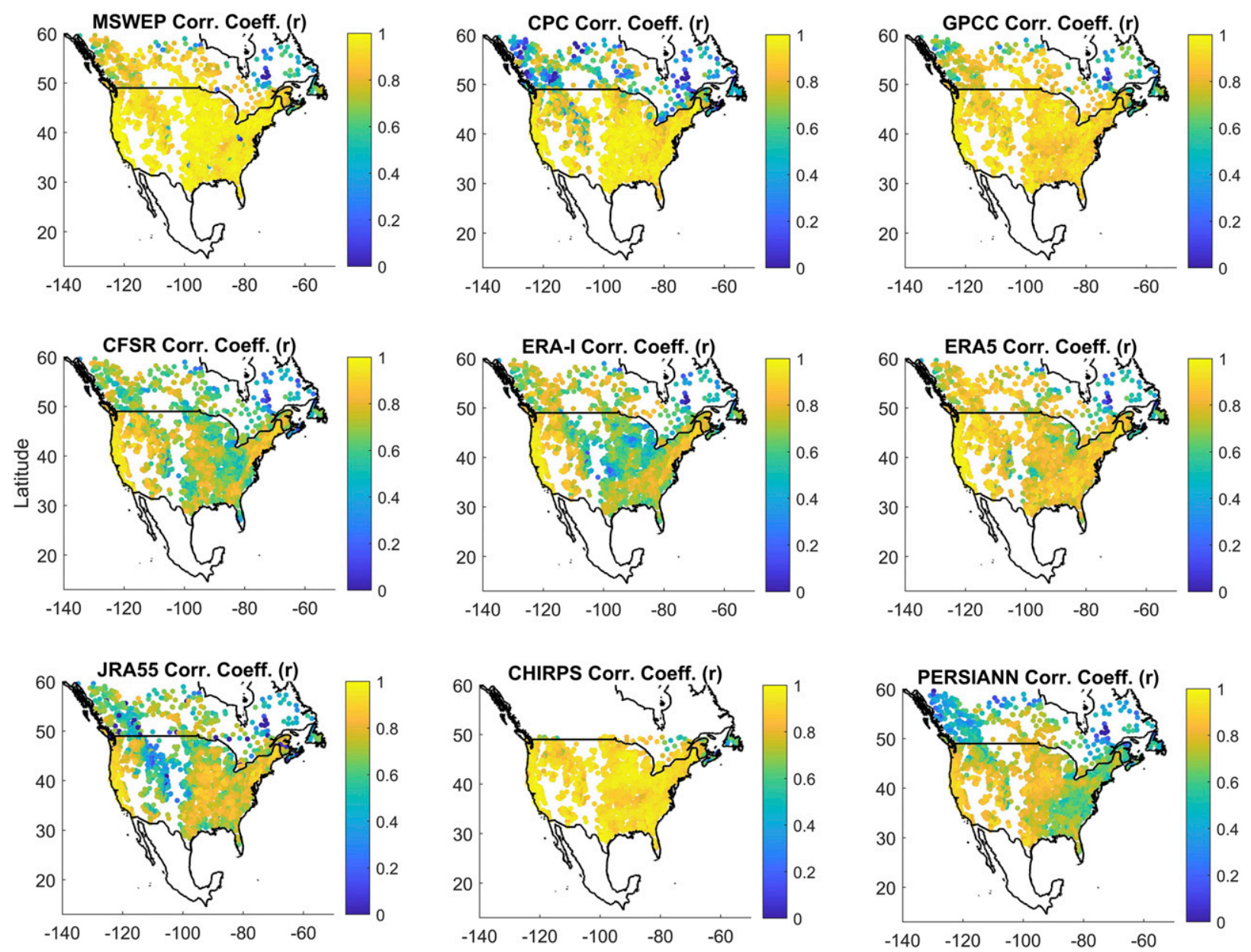

FIG. 8. The spatial distribution of correlation coefficients computed at the daily time step.

Results imply that a low-density station network narrows the gap between the reanalyses and gauge-based products. Reanalyses do not assimilate surface precipitation in their analysis scheme, and are therefore much less affected by a lack of ground precipitation measurements (either sparse station network or precipitation undercatch in gauged locations). This suggests that ERA5 precipitation is as robust as the best gauged products above $50^{\circ} \mathrm{N}$ and reanalyses should therefore be considered as good candidates in regions with deficient observational networks, confirming the conclusions of Tarek et al. (2020).

The spatial and temporal resolution of the datasets reviewed in this work differ widely. The temporal resolution itself (hourly to subdaily) was not investigated. The spatial resolution of the above products, which varies from $0.05^{\circ}$ to $1^{\circ}$, was summarily evaluated by analyzing hydrological modeling performance with respect to watershed size and by elevation, on the basis that higher-resolution datasets would perform better on smaller watersheds, or for high-elevation watersheds, where the topography is more complex. No clear link was found between dataset performance and either size or elevation (results not shown). The main notable result was a clear improvement of ERA5 over ERA-Interim for high-elevation catchments. This suggests that the fourfold resolution difference between the highest- and lowest-resolution datasets is not large enough to make a difference in this type of application, or that the use of a global hydrological model (which requires the averaging of the contributing grid points irrespective of their resolution) is not ideal to investigate the impact of resolution. Most of the selected watersheds are relatively large and therefore have a response time larger than one day. On those watersheds, the averaging of input data coupled with the smoothed hydrographs from the global hydrological models result in differences that are very difficult to see when using a criterion such as the KGE metric. Other metrics (e.g., peak flow reproduction, streamflow variance) may have been better suited to study the impact of dataset resolution (e.g., Kokkonen and Jakeman 2001). The conceptualized nature of the hydrological models used in this study may also not be best suited to outline such differences. For the smaller watersheds in our database, subdaily modeling would be better suited (Bevelhimer et al. 2015), but was not feasible since most datasets are limited to the daily time step. The use of a distributed hydrological model may be preferable to study the impacts of data resolution. 

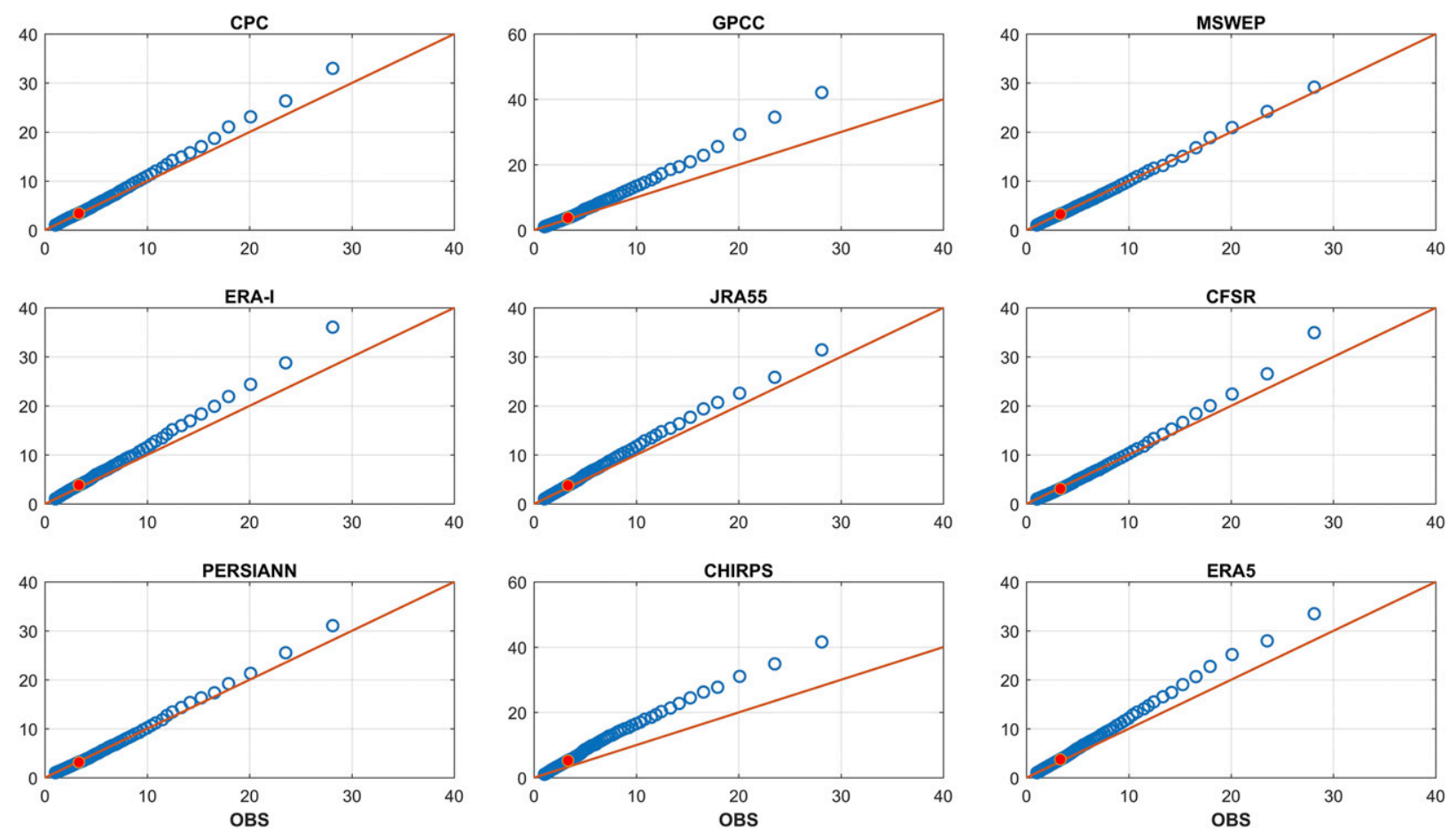

FIG. 9. Quantile-quantile precipitation plots (0.01-0.99 at a 0.01 interval) for the Saint Louis River catchment in Minnesota (United States). The median (quantile 0.5 ) is represented by the solid red circle.

The results show that among all datasets tested in this study, MSWEP either is the best dataset, or is tied for best. In addition, MSWEP provides the second-highest spatial and temporal resolutions of all datasets. The performance of MSWEP demonstrates the potential of merged products in providing high-quality outputs, by utilizing and integrating all available information. In high network density regions, MSWEP weighs observations heavily, but also relies heavily on reanalysis when weather station observation networks are less dense, such as in northern Canada. We can expect an increasing number of datasets to rely on multisource information at the regional and global scales. At the regional scale, for example, highresolution datasets can be obtained by combining groundbased radars and weather stations (Lespinas et al. 2015;

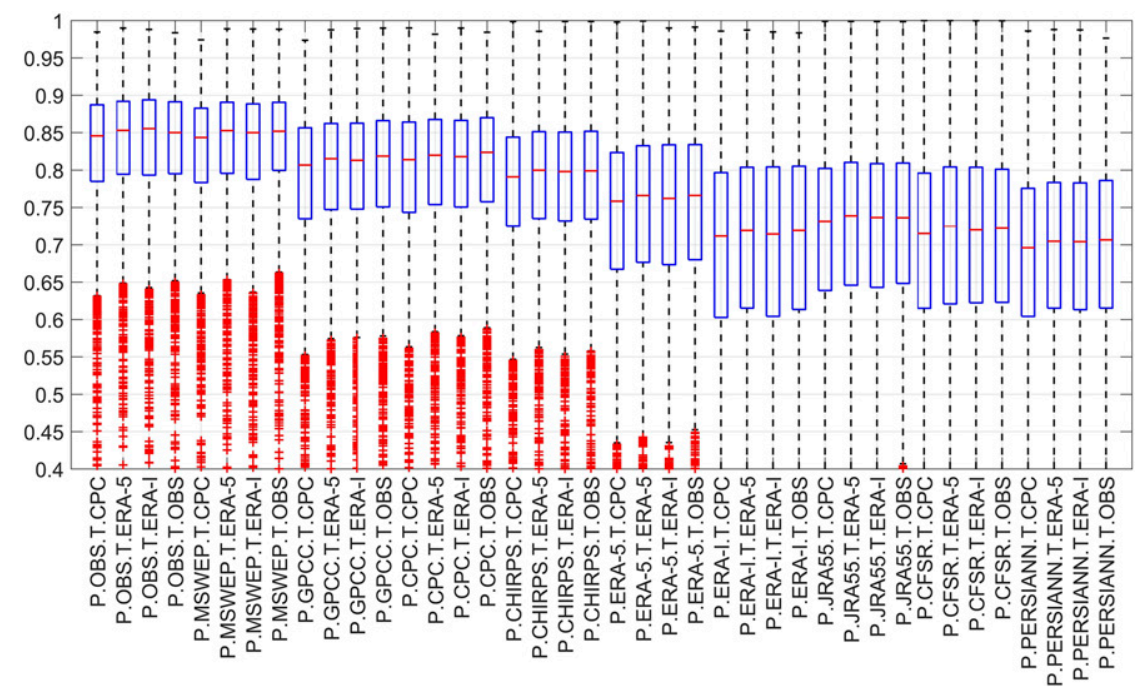

FIG. 10. KGE boxplots of simulated streamflows (below $50^{\circ} \mathrm{N}$ latitude) from 10 precipitation datasets and four temperature datasets (40 combinations) using HMETS. 


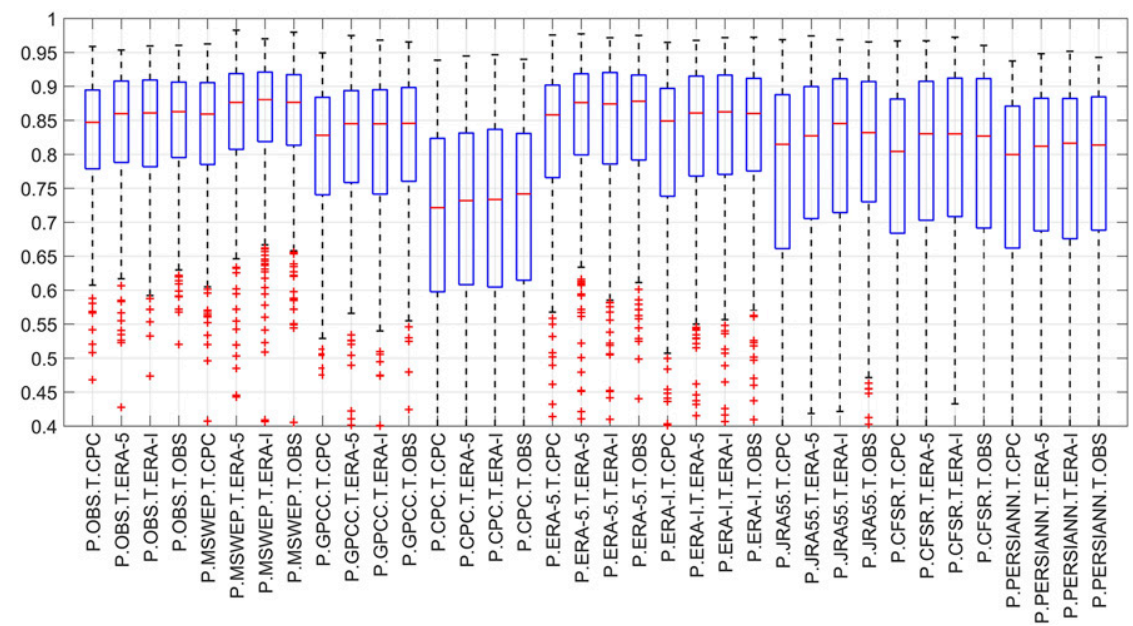

FIG. 11. KGE boxplots of simulated streamflow for nine precipitation datasets and four temperature datasets (36 combinations) using HMETS (above $50^{\circ} \mathrm{N}$ ). Note that CHIRPS V2.0 does not provide data beyond $\pm 50^{\circ}$ latitude and is excluded from this comparison.

Shen et al. 2018). In addition, there are other potential reasons for the excellent MSWEP results. MSWEP is the closest relative (in terms of construction and resolution) to the chosen reference dataset $(\mathrm{NACH} 2 \mathrm{H})$ and especially over the United States. Over Canada, MSWEP relies to a much larger extent on reanalysis and is therefore not as closely related to $\mathrm{NACH} 2 \mathrm{H}$. In addition, MSWEP uses streamflow data in its merging scheme, which may give it an advantage over the other datasets in terms of long-term biases. The use of streamflow data by MSWEP is, however, limited to long-term mean streamflow corrections, and only in regions with snowfall and/or complex topography. It is unlikely that this procedure has noticeable impacts on hydrological modeling performance at the daily scale.

CHIRPS performed very well for most of the comparison criteria. It performed better during the warm seasons, owing to its limitation in terms of detecting snowfall. It had a high correlation value $(0.93)$ with the reference dataset as well as the second-lowest mean absolute and root-mean-square errors. CHIRPS, which integrates satellite and gauge stations data on a high spatial resolution grid of $0.05^{\circ}$, has been shown to be a viable choice in climatological studies. Other studies have
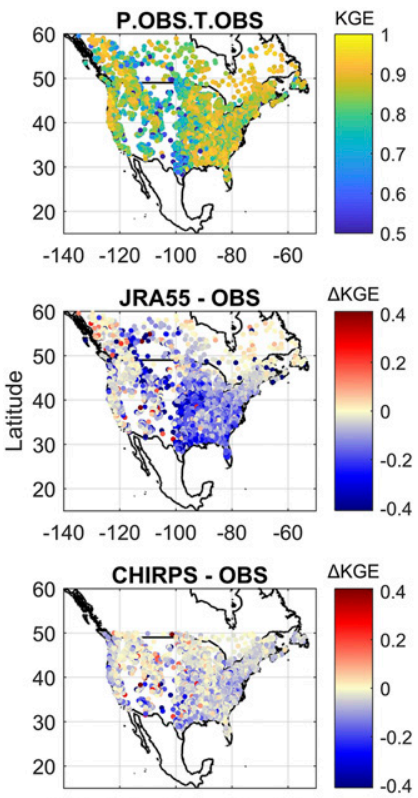

$\begin{array}{lllll}-140 & -120 & -100 & -80 & -60\end{array}$

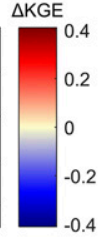

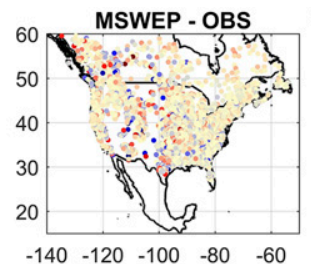

CFSR - OBS
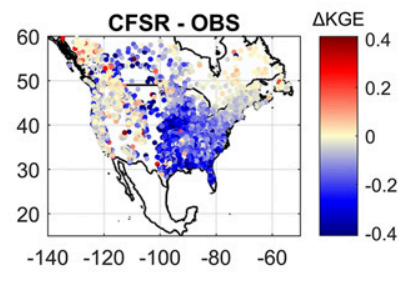

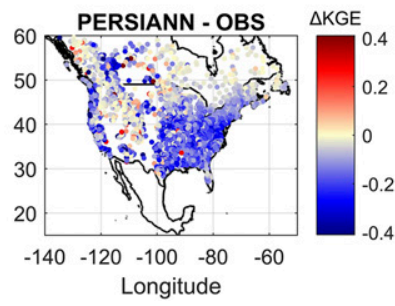

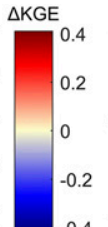
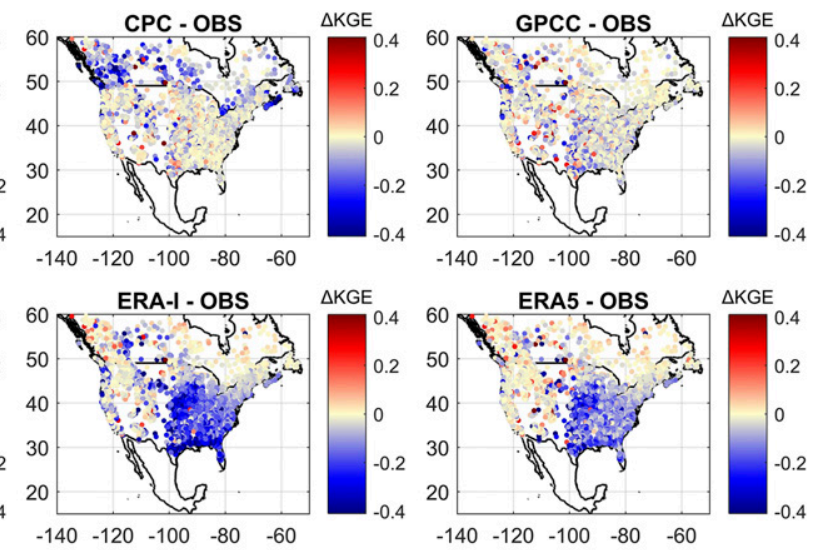

$\begin{array}{lllll}-140 & -120 & -100 & -80 & -60\end{array}$

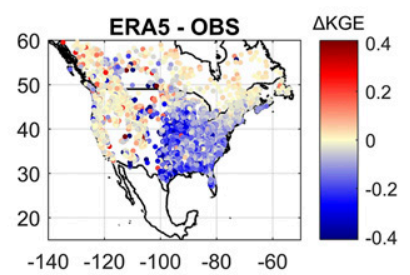

FIG. 12. Spatial distribution maps for the KGE difference between the observed precipitation dataset combined with the observed temperature dataset (top-left plot) and the nine precipitation datasets combined with the observed temperature dataset. 

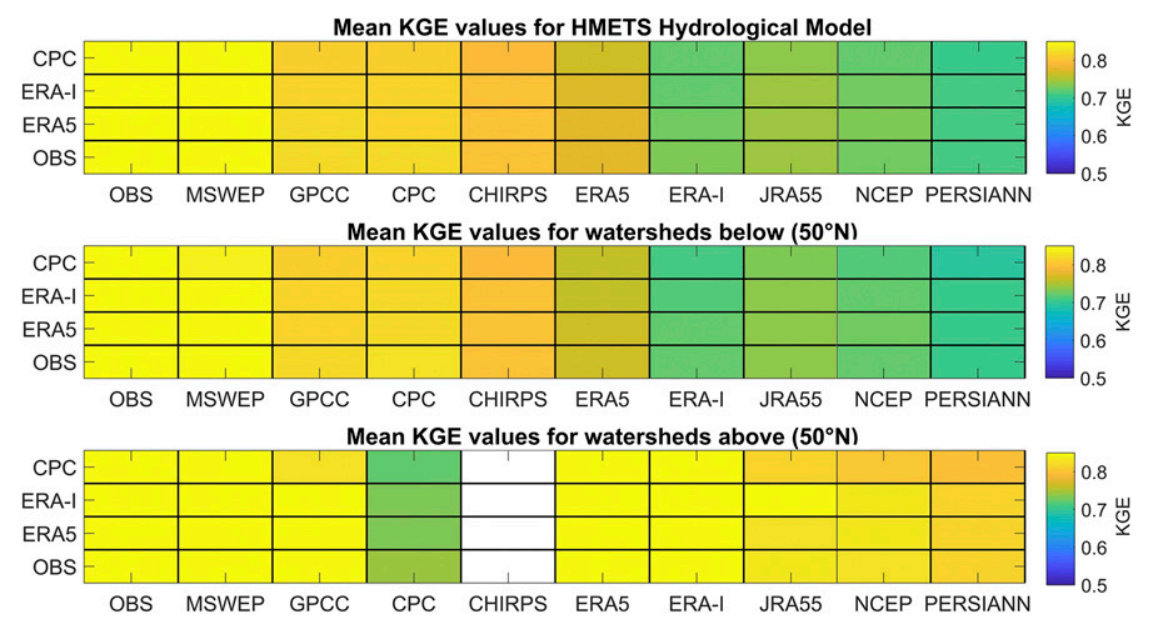

FIG. 13. (top) Mean KGE values for all catchments, (middle) catchments below $50^{\circ} \mathrm{N}$ latitude, and (bottom) catchments above $50^{\circ} \mathrm{N}$ latitude for 10 precipitation datasets and four temperature datasets. CHIRPS does not provide data beyond $\pm 50^{\circ}$ latitude and is shown in white.

indeed mentioned its quality in this regard (Toté et al. 2015; Duan et al. 2016; Poméon et al. 2017; Beck et al. 2017b; Duan et al. 2019).

For hydrological modeling, the results in this study have shown that, in general, gauge-based datasets perform better than reanalyses, whereas the performance of the two selected satellite products differ widely, with CHIRPS clearly outperforming PERSIANN. CPC is the worst gauge-only product, especially so over Canada. A few relevant studies have assessed the influence of gauge density on climate data (Arsenault and Brissette 2014; Gubler et al. 2017; Hofstra et al. 2010; Janis et al. 2004). In particular, Janis et al. (2002) evaluated the required station density to capture the regional climate variability in the United States. The study reported that a station density of 1 station per $180 \mathrm{~km}^{2}$ would be needed to adequately monitor the climate variability.

ERA5 presents clear improvements over its predecessor (ERA-Interim) and is the best reanalysis product for hydrological modeling among those used in this study. ERA5 shines brightly, particularly above $50^{\circ} \mathrm{N}$. The high spatial $\left(0.25^{\circ}\right)$ and temporal $(1 \mathrm{~h})$ resolutions of ERA5 and the fact that it is available in near-real time lends it a significant advantage over most of the other datasets. The ECMWF recently launched the ERA5-Land reanalysis at a $0.1^{\circ}$ resolution. It uses the same assimilation process as ERA5, but is run at a finer resolution over land. Reanalyses could be considered as extremely complex multisource merged products, and are likely to gain in importance in the near future. Their main limitation, when compared to MSWEP, for example, is that they do not integrate precipitation gauge data into the assimilation scheme. Reanalyses are very likely to be supported and improved in the future, as compared to the other datasets used in this study, which do not rely on recurrent national funding, and which often result from the efforts of small teams. Reanalysis performed worse than gauge-based products below $50^{\circ} \mathrm{N}$, and particularly so in the eastern half of the United States.
Essou et al. (2016) showed that reanalysis had difficulties reproducing the seasonal cycle of precipitation over this region. Reanalysis precipitation could easily be postprocessed at the monthly scale using observations to palliate this problem, as was previously done on older reanalysis products (Weedon et al. 2014).

Overall, results show that gauge-based datasets should be preferred in regions with good weather network density, with MSWEP being clearly the best performing dataset as represented by its results below $50^{\circ} \mathrm{N}$. Above this latitude, where observational network density is much poorer, ERA5 performs just as well as MSWEP and the reference dataset. This indicates that ERA5, and potentially CHIRPS would be good choices as reference datasets for climate change impact studies in data-sparse regions.

\section{Conclusions}

The performance of nine precipitation and three temperature global gridded dataset products was assessed in this paper in a two-step process. The datasets were first compared against two high-resolution regional gridded datasets over the United States and Canada. Performance was evaluated over 3138 North American catchments using annual and seasonal biases, mean error (ME), mean absolute error (MAE), root-mean-square error (RMSE), and coefficient of correlation $(r)$. In a second step, streamflows were simulated using all 40 possible combinations of precipitation and temperature datasets over 3138 North American catchments, and compared against data from gauging stations. Results showed that precipitation datasets are the main driver of uncertainty due to the relatively large differences between the datasets. Comparatively, differences between temperature datasets played a much smaller role as all four products behave very similarly. Temperature derived from observations and from the ERA5 reanalysis provided marginally, but consistently 
better, results than the other two tested temperature datasets. For precipitation, overall, the merged-product MSWEP consistently performed best. Both gauge-based global products performed well over the United States, but their performance decreased over Canada (and particularly in the case of CPC Unified), where observations are based on a less dense observational network. The ERA5 reanalysis performed really well over Canada and the western United States, but its overall performance was affected by a relatively poorer performance over the eastern United States. It clearly outperformed the other three tested reanalyses. CHIRPS was found to be easily the best-performing satellite precipitation dataset, outperforming PERSIANN and all reanalysis, with the exception of ERA5.

Acknowledgments. This study was partially funded by the National Science and Engineering Research Council of Canada (RGPIN-2015-05048 and RGPIN-2018-04872) and the Egyptian Armed Forces (Ministry of Defense).

Data availability statement. The CPC, GPCC and NCEP datasets can be downloaded from the Earth System Research Laboratory (ESRL), available here: https://www.esrl.noaa.gov/ psd/data/gridded/tables/precipitation.html. ERA-Interim, ERA5, and JRA55 datasets are available on the Research Data Archive: https://rda.ucar.edu/datasets/ds628.0/. MSWEP data are available through the PCA servers at: https://platform.princetonclimate.com/ PCA_Platform/mswepRetro.html. The CHIRPS satellite dataset can be downloaded from the Climate Hazards Center: https:// www.chc.ucsb.edu/data/chirps. Finally, the HMETS hydrological model is available on the MATLAB File Exchange: https:// www.mathworks.com/matlabcentral/fileexchange/48069-hmetshydrological-model.

\section{REFERENCES}

Ahmed, K. F., G. Wang, J. Silander, A. M. Wilson, J. M. Allen, R. Horton, and R. Anyah, 2013: Statistical downscaling and bias correction of climate model outputs for climate change impact assessment in the U.S. northeast. Global Planet. Change, 100, 320-332, https://doi.org/10.1016/j.gloplacha.2012.11.003.

Andermann, C., S. Bonnet, and R. Gloaguen, 2011: Evaluation of precipitation data sets along the Himalayan front. Geochem. Geophys. Geosyst., 12, Q07023, https://doi.org/ 10.1029/2011GC003513.

Arsenault, R., and F. Brissette, 2014: Determining the optimal spatial distribution of weather station networks for hydrological modeling purposes using RCM datasets: An experimental approach. J. Hydrometeor., 15, 517-526, https:// doi.org/10.1175/JHM-D-13-088.1.

—, A. Poulin, P. Côté, and F. Brissette, 2014: Comparison of stochastic optimization algorithms in hydrological model calibration. J. Hydrol. Eng., 19, 1374-1384, https://doi.org/ 10.1061/(ASCE)HE.1943-5584.0000938.

_ , F. Brissette, and J.-L. Martel, 2018: The hazards of split-sample validation in hydrological model calibration. J. Hydrol., 566, 346-362, https://doi.org/10.1016/j.jhydrol.2018.09.027.

$\longrightarrow,-$ J. Chen, Q. Guo, and G. Dallaire, 2020: NAC2H: The North-American climate change and hydroclimatology dataset. Water Resour. Res., 56, e2020WR027097, https://doi.org/ 10.1029/2020WR027097.
Ashouri, H., K.-L. Hsu, S. Sorooshian, D. K. Braithwaite, K. R. Knapp, L. D. Cecil, B. R. Nelson, and O. P. Prat, 2015: PERSIANN-CDR: Daily precipitation climate data record from multisatellite observations for hydrological and climate studies. Bull. Amer. Meteor. Soc., 96, 69-83, https://doi.org/ 10.1175/BAMS-D-13-00068.1.

Aslami, F., A. Ghorbani, B. Sobhani, and A. Esmali, 2019: Comprehensive comparison of daily IMERG and GSMaP satellite precipitation products in Ardabil Province, Iran. Int. J. Remote Sens., 40, 3139-3153, https://doi.org/10.1080/ 01431161.2018 .1539274$.

Asong, Z., S. Razavi, H. Wheater, and J. Wong, 2017: Evaluation of Integrated Multisatellite Retrievals for GPM (IMERG) over southern Canada against ground precipitation observations: A preliminary assessment. J. Hydrometeor., 18, 1033-1050, https://doi.org/10.1175/JHM-D-16-0187.1.

Awange, J., V. Ferreira, E. Forootan, S. Andam-Akorful, N. Agutu, and X. He, 2016: Uncertainties in remotely sensed precipitation data over Africa. Int. J. Climatol., 36, 303-323, https://doi.org/ 10.1002/joc.4346.

Beck, H. E., A. I. Van Dijk, V. Levizzani, J. Schellekens, D. Gonzalez Miralles, B. Martens, and A. De Roo, 2017a: MSWEP: 3-hourly 0.25 global gridded precipitation (1979-2015) by merging gauge, satellite, and reanalysis data. Hydrol. Earth Syst. Sci., 21, 589-615, https://doi.org/10.5194/hess-21-589-2017. _, and Coauthors, 2017b: Global-scale evaluation of 22 precipitation datasets using gauge observations and hydrological modeling. Hydrol. Earth Syst. Sci., 21, 6201-6217, https:// doi.org/10.5194/hess-21-6201-2017.

Behrangi, A., B. Khakbaz, T. C. Jaw, A. AghaKouchak, K. Hsu, and S. Sorooshian, 2011: Hydrologic evaluation of satellite precipitation products over a mid-size basin. J. Hydrol., 397, 225-237, https://doi.org/10.1016/j.jhydrol.2010.11.043.

Bevelhimer, M. S., R. A. McManamay, and B. O'Connor, 2015: Characterizing sub-daily flow regimes: Implications of hydrologic resolution on ecohydrology studies. River Res. Appl., 31, 867-879, https://doi.org/10.1002/rra.2781.

Boers, N., B. Bookhagen, J. Marengo, N. Marwan, J.-S. von Storch, and J. Kurths, 2015: Extreme rainfall of the South American monsoon system: A dataset comparison using complex networks. J. Climate, 28, 1031-1056, https://doi.org/ 10.1175/JCLI-D-14-00340.1.

Bosilovich, M. G., 2013: Regional climate and variability of NASA MERRA and recent reanalyses: U.S. summertime precipitation and temperature. J. Appl. Meteor. Climatol., 52, 19391951, https://doi.org/10.1175/JAMC-D-12-0291.1.

Chen, M., W. Shi, P. Xie, V. B. Silva, V. E. Kousky, R. Wayne Higgins, and J. E. Janowiak, 2008: Assessing objective techniques for gauge-based analyses of global daily precipitation. J. Geophys. Res., 113, D04110, https://doi.org/10.1029/ 2007JD009132.

Chen, S., and Coauthors, 2014: Evaluation of high-resolution precipitation estimates from satellites during July 2012 Beijing flood event using dense rain gauge observations. PLOS ONE, 9 , e89681, https://doi.org/10.1371/JOURNAL.PONE.0089681.

Chen, Z., Y. Qin, Y. Shen, and S. Zhang, 2016: Evaluation of global satellite mapping of precipitation project daily precipitation estimates over the Chinese mainland. Adv. Meteor., 2016, 9365294, http://doi.org/10.1155/2016/9365294.

Colston, J. M., and Coauthors, 2018: Evaluating meteorological data from weather stations, and from satellites and global models for a multi-site epidemiological study. Environ. Res., 165, 91-109, https://doi.org/10.1016/j.envres.2018.02.027. 
Dee, D. P., and Coauthors, 2011: The ERA-Interim Reanalysis: Configuration and performance of the data assimilation system. Quart. J. Roy. Meteor. Soc., 137, 553-597, https://doi.org/ 10.1002/qj.828.

Deser, C., A. Phillips, V. Bourdette, and H. Teng, 2012: Uncertainty in climate change projections: The role of internal variability. Climate Dyn., 38, 527-546, https://doi.org/10.1007/s00382-0100977-x.

Di Luzio, M., G. L. Johnson, C. Daly, J. K. Eischeid, and J. G. Arnold, 2008: Constructing retrospective gridded daily precipitation and temperature datasets for the conterminous United States. J. Appl. Meteor. Climatol., 47, 475-497, https:// doi.org/10.1175/2007JAMC1356.1.

Duan, Z., J. Liu, Y. Tuo, G. Chiogna, and M. Disse, 2016: Evaluation of eight high spatial resolution gridded precipitation products in Adige Basin (Italy) at multiple temporal and spatial scales. Sci. Total Environ., 573, 1536-1553, https:// doi.org/10.1016/j.scitotenv.2016.08.213.

—, Y. Tuo, J. Liu, H. Gao, X. Song, Z. Zhang, L. Yang, and D. F. Mekonnen, 2019: Hydrological evaluation of open-access precipitation and air temperature datasets using SWAT in a poorly gauged basin in Ethiopia. J. Hydrol., 569, 612-626, https://doi.org/10.1016/j.jhydrol.2018.12.026.

Essou, G. R., R. Arsenault, and F. P. Brissette, 2016: Comparison of climate datasets for lumped hydrological modeling over the continental United States. J. Hydrol., 537, 334-345, https:// doi.org/10.1016/j.jhydrol.2016.03.063.

Funk, C., and Coauthors, 2015: The climate hazards infrared precipitation with stations-A new environmental record for monitoring extremes. Sci. Data, 2, 150066, https://doi.org/ 10.1038/sdata.2015.66.

Getirana, A. C., J. Espinoza, J. Ronchail, and O. Rotunno Filho, 2011: Assessment of different precipitation datasets and their impacts on the water balance of the Negro River basin. J. Hydrol., 404, 304-322, https://doi.org/10.1016/ j.jhydrol.2011.04.037.

Giardino, C., M. Bresciani, P. Villa, and A. Martinelli, 2010: Application of remote sensing in water resource management: The case study of lake Trasimeno, Italy. Water Resour. Manage., 24, 3885-3899, https://doi.org/10.1007/s11269-0109639-3.

Gubler, S., and Coauthors, 2017: The influence of station density on climate data homogenization. Int. J. Climatol., 37, 4670-4683, https://doi.org/10.1002/joc.5114.

Gupta, H. V., H. Kling, K. K. Yilmaz, and G. F. Martinez, 2009: Decomposition of the mean squared error and NSE performance criteria: Implications for improving hydrological modelling. J. Hydrol., 377, 80-91, https://doi.org/10.1016/ j.jhydrol.2009.08.003.

Gutenson, J. L., A. A. Tavakoly, M. D. Wahl, and M. L. Follum, 2020: Comparison of generalized non-data-driven reservoir routing models for global-scale hydrologic modeling. Hydrol. Earth Syst. Sci., 24, 2711-2729, https://doi.org/10.5194/hess-24-2711-2020.

Hansen, N., S. D. Müller, and P. Koumoutsakos, 2003: Reducing the time complexity of the derandomized evolution strategy with covariance matrix adaptation (CMA-ES). Evol. Comput., 11, 1-18, https://doi.org/10.1162/106365603321828970.

Henn, B., A. J. Newman, B. Livneh, C. Daly, and J. D. Lundquist, 2018: An assessment of differences in gridded precipitation datasets in complex terrain. J. Hydrol., 556, 1205-1219, https:// doi.org/10.1016/j.jhydrol.2017.03.008.

Hersbach, H., and D. Dee, 2016: ERA5 reanalysis is in production. ECMWF Newsletter, No. 147, ECMWF, Reading, United
Kingdom, 7, http://www.ecmwf.int/sites/default/files/elibrary/ 2016/16299-newsletter-no147-spring-2016.pdf.

Hobeichi, S., G. Abramowitz, S. Contractor, and J. Evans, 2020a: Evaluating precipitation datasets using surface water and energy budget closure. J. Hydrometeor., 21, 989-1009, https:// doi.org/10.1175/JHM-D-19-0255.1.

$\longrightarrow$, - - and J. Evans, 2020b: Conserving Land-Atmosphere Synthesis Suite (CLASS). J. Climate, 33, 1821-1844, https:// doi.org/10.1175/JCLI-D-19-0036.1.

Hofstra, N., M. New, and C. McSweeney, 2010: The influence of interpolation and station network density on the distributions and trends of climate variables in gridded daily data. Climate Dyn., 35, 841-858, https://doi.org/10.1007/s00382-009-0698-1.

Hou, A. Y., and Coauthors, 2014: The Global Precipitation Measurement mission. Bull. Amer. Meteor. Soc., 95, 701-722, https://doi.org/10.1175/BAMS-D-13-00164.1.

Huffman, G. J., D. T. Bolvin, D. Braithwaite, K. Hsu, R. Joyce, C. Kidd, E. J. Nelkin, and P. Xie, 2015: NASA Global Precipitation Measurement Integrated Multi-satellitE Retrievals for GPM (IMERG). Algorithm Theoretical Basis Doc., version 4.5, $30 \mathrm{pp}$., http://pmm.nasa.gov/sites/default/files/document_files/ IMERG_ATBD_V4.5.pdf.

Isotta, F. A., and Coauthors, 2014: The climate of daily precipitation in the Alps: Development and analysis of a highresolution grid dataset from pan-Alpine rain-gauge data. Int. J. Climatol., 34, 1657-1675, https://doi.org/10.1002/joc.3794.

Janis, M., K. Hubbard, and K. Redmond, 2002: Determining the optimal number of stations for the United States Climate Reference Network. Final Rep., Southeast Regional Climate Center, Researh Paper Series, 21 pp.

Janis, M. J., K. G. Hubbard, and K. T. Redmond, 2004: Station density strategy for monitoring long-term climatic change in the contiguous United States. J. Climate, 17, 151-162, https://doi.org/ 10.1175/1520-0442(2004)017<0151:SDSFML > 2.0.CO;2.

Jiang, S., L. Ren, Y. Hong, B. Yong, X. Yang, F. Yuan, and M. Ma, 2012: Comprehensive evaluation of multi-satellite precipitation products with a dense rain gauge network and optimally merging their simulated hydrological flows using the Bayesian model averaging method. J. Hydrol., 452-453, 213-225, https:// doi.org/10.1016/j.jhydrol.2012.05.055.

Joyce, R. J., J. E. Janowiak, P. A. Arkin, and P. Xie, 2004: CMORPH: A method that produces global precipitation estimates from passive microwave and infrared data at high spatial and temporal resolution. J. Hydrometeor., 5, 487-503, https://doi.org/10.1175/1525-7541(2004)005<0487: CAMTPG $>2.0 . \mathrm{CO} ; 2$.

Jutla, A., H. Aldaach, H. Billian, A. Akanda, A. Huq, and R. Colwell, 2015: Satellite based assessment of hydroclimatic conditions related to cholera in Zimbabwe. PLoS One, 10, e0137828, https://doi.org/10.1371/journal.pone.0137828.

Kang, S., and J.-B. Ahn, 2015: Global energy and water balances in the latest reanalyses. Asia-Pac. J. Atmos. Sci., 51, 293-302, https://doi.org/10.1007/s13143-015-0079-0.

Khan, S. I., and Coauthors, 2011: Hydroclimatology of Lake Victoria region using hydrologic model and satellite remote sensing data. Hydrol. Earth Syst. Sci., 15, 107-117, https:// doi.org/10.5194/hess-15-107-2011.

Kidd, C., P. Bauer, J. Turk, G. Huffman, R. Joyce, K.-L. Hsu, and D. Braithwaite, 2012: Intercomparison of high-resolution precipitation products over northwest Europe. J. Hydrometeor., 13, 67-83, https://doi.org/10.1175/JHM-D-11-042.1.

Kling, H., M. Fuchs, and M. Paulin, 2012: Runoff conditions in the upper Danube basin under an ensemble of climate 
change scenarios. J. Hydrol., 424-425, 264-277, https:// doi.org/10.1016/j.jhydrol.2012.01.011.

Kobayashi, S., and Coauthors, 2015: The JRA-55 reanalysis: General specifications and basic characteristics. J. Meteor. Soc. Japan, 93, 5-48, https://doi.org/10.2151/jmsj.2015-001.

Kokkonen, T. S., and A. J. Jakeman, 2001: A comparison of metric and conceptual approaches in rainfall-runoff modeling and its implications. Water Resour. Res., 37, 2345-2352, https:// doi.org/10.1029/2001WR000299.

Laviola, S., V. Levizzani, E. Cattani, and C. Kidd, 2013: The 183-WSL fast rain rate retrieval algorithm. Part II: Validation using ground radar measurements. Atmos. Res., 134, 77-86, https:// doi.org/10.1016/j.atmosres.2013.07.013.

Lawrimore, J. H., M. J. Menne, B. E. Gleason, C. N. Williams, D. B. Wuertz, R. S. Vose, and J. Rennie, 2011: An overview of the Global Historical Climatology Network monthly mean temperature data set, version 3.J. Geophys. Res., 116, D19121, https://doi.org/10.1029/2011JD016187.

Lespinas, F., V. Fortin, G. Roy, P. Rasmussen, and T. Stadnyk, 2015: Performance evaluation of the Canadian Precipitation Analysis (CaPA). J. Hydrometeor., 16, 2045-2064, https:// doi.org/10.1175/JHM-D-14-0191.1.

Lockhoff, M., O. Zolina, C. Simmer, and J. Schulz, 2014: Evaluation of satellite-retrieved extreme precipitation over Europe using gauge observations. J. Climate, 27, 607-623, https://doi.org/10.1175/JCLI-D-13-00194.1.

Lorenz, C., H. Kunstmann, B. Devaraju, M. J. Tourian, N. Sneeuw, and J. Riegger, 2014: Large-scale runoff from landmasses: A global assessment of the closure of the hydrological and atmospheric water balances. J. Hydrometeor., 15, 2111-2139, https://doi.org/10.1175/JHM-D-13-0157.1.

Lu, D., and B. Yong, 2018: Evaluation and hydrological utility of the latest GPM IMERG V5 and GSMaP V7 precipitation products over the Tibetan Plateau. Remote Sens., 10, 2022, https://doi.org/10.3390/rs10122022.

Martel, J.-L., K. Demeester, F. P. Brissette, R. Arsenault, and A. Poulin, 2017: HMET: A simple and efficient hydrology model for teaching hydrological modelling, flow forecasting and climate change impacts. Int. J. Eng. Educ., 33, 1307-1316.

— A. Mailhot, F. Brissette, and D. Caya, 2018: Role of natural climate variability in the detection of anthropogenic climate change signal for mean and extreme precipitation at local and regional scales. J. Climate, 31, 4241-4263, https://doi.org/ 10.1175/JCLI-D-17-0282.1.

Martens, B., P. Cabus, I. De Jongh, and N. Verhoest, 2013: Merging weather radar observations with ground-based measurements of rainfall using an adaptive multiquadric surface fitting algorithm. J. Hydrol., 500, 84-96, https://doi.org/10.1016/j.jhydrol.2013.07.011.

Mazzoglio, P., F. Laio, S. Balbo, P. Boccardo, and F. Disabato, 2019: Improving an extreme rainfall detection system with GPM IMERG data. Remote Sens., 11, 677, https://doi.org/ 10.3390/rs11060677.

Munier, S., and F. Aires, 2018: A new global method of satellite dataset merging and quality characterization constrained by the terrestrial water budget. Remote Sens. Environ., 205, 119130, https://doi.org/10.1016/j.rse.2017.11.008.

Nash, J. E., and J. V. Sutcliffe, 1970: River flow forecasting through conceptual models Part I-A discussion of principles. J. Hydrol., 10, 282-290, https://doi.org/10.1016/00221694(70)90255-6.

Nashwan, M. S., S. Shahid, and X. Wang, 2019: Uncertainty in estimated trends using gridded rainfall data: A case study of Bangladesh. Water, 11, 349, https://doi.org/10.3390/w11020349.
Nicholson, S. E., 2013: The West African Sahel: A review of recent studies on the rainfall regime and its interannual variability. ISRN Meteor., 2013, 453521, https://doi.org/10.1155/2013/ 453521.

Nieto, H., I. Sandholt, I. Aguado, E. Chuvieco, and S. Stisen, 2011: Air temperature estimation with MSG-SEVIRI data: Calibration and validation of the TVX algorithm for the Iberian Peninsula. Remote Sens. Environ., 115, 107-116, https://doi.org/10.1016/j.rse.2010.08.010.

Nishat, B., and S. M. Rahman, 2009: Water resources modeling of the Ganges-Brahmaputra-Meghna river basins using satellite remote sensing data 1. J. Amer. Water Resour. Assoc., 45, 1313-1327, https://doi.org/10.1111/j.1752-1688.2009.00374.x.

Okamoto, K., T. Ushio, T. Iguchi, N. Takahashi, and K. Iwanami, 2005: The Global Satellite Mapping of Precipitation (GSMaP) project. Proc. 2005 IEEE Int. Geoscience and Remote Sensing Symp., Seoul, South Korea, IEEE, 3414-3416, https://doi.org/ 10.1109/IGARSS.2005.1526575.

Oudin, L., F. Hervieu, C. Michel, C. Perrin, V. Andréassian, F. Anctil, and C. Loumagne, 2005: Which potential evapotranspiration input for a lumped rainfall-runoff model?: Part 2-Towards a simple and efficient potential evapotranspiration model for rainfall-runoff modelling. J. Hydrol., 303, 290 306, https://doi.org/10.1016/j.jhydrol.2004.08.026.

Pechlivanidis, I. G., and B. Arheimer, 2015: Large-scale hydrological modelling by using modified PUB recommendations: The India-HYPE case. Hydrol. Earth Syst. Sci., 19, 4559-4579, https://doi.org/10.5194/hess-19-4559-2015.

Poméon, T., D. Jackisch, and B. Diekkrüger, 2017: Evaluating the performance of remotely sensed and reanalysed precipitation data over West Africa using HBV light. J. Hydrol., 547, 222235, https://doi.org/10.1016/j.jhydrol.2017.01.055.

Prakash, S., R. Gairola, and A. Mitra, 2015a: Comparison of largescale global land precipitation from multisatellite and reanalysis products with gauge-based GPCC data sets. Theor. Appl. Climatol., 121, 303-317, https://doi.org/10.1007/s00704014-1245-5.

— vational rainfall datasets over India during the southwest monsoon season. Int. J. Climatol., 35, 2326-2338, https:// doi.org/10.1002/joc.4129.

—, M. R. Kumar, S. Mathew, and R. Venkatesan, 2018: How accurate are satellite estimates of precipitation over the north Indian Ocean? Theor. Appl. Climatol., 134, 467-475, https:// doi.org/10.1007/s00704-017-2287-2.

Prein, A. F., and A. Gobiet, 2017: Impacts of uncertainties in European gridded precipitation observations on regional climate analysis. Int. J. Climatol., 37, 305-327, https://doi.org/ 10.1002/joc. 4706 .

Romilly, T., and M. Gebremichael, 2011: Evaluation of satellite rainfall estimates over Ethiopian river basins. Hydrol. Earth Syst. Sci., 15, 1505-1514, http://doi.org/10.5194/hess-15-1505-2011.

Saha, S., and Coauthors, 2010: The NCEP Climate Forecast System Reanalysis. Bull. Amer. Meteor. Soc., 91, 1015-1058, https:// doi.org/10.1175/2010BAMS3001.1.

Schneider, U., A. Becker, P. Finger, A. Meyer-Christoffer, M. Ziese, and B. Rudolf, 2014: GPCC's new land surface precipitation climatology based on quality-controlled in situ data and its role in quantifying the global water cycle. Theor. Appl. Climatol., 115, 15-40, https://doi.org/10.1007/s00704013-0860-x.

Sheffield, J., C. R. Ferguson, T. J. Troy, E. F. Wood, and M. F. McCabe, 2009: Closing the terrestrial water budget from satellite 
remote sensing. Geophys. Res. Lett., 36, L07403, https://doi.org/ 10.1029/2009GL037338.

Shen, Y., Z. Hong, Y. Pan, J. Yu, and L. Maguire, 2018: China's $1 \mathrm{~km}$ merged gauge, radar and satellite experimental precipitation dataset. Remote Sens., 10, 264, https://doi.org/10.3390/ rs10020264.

Siddique-E-Akbor, A. H. M., F. Hossain, S. Sikder, C. K. Shum, S. Tseng, Y. Yi, F. J. Turk, and A. Limaye, 2014: Satellite precipitation data-driven hydrological modeling for water resources management in the Ganges, Brahmaputra, and Meghna basins. Earth Interact., 18, https://doi.org/10.1175/EID-14-0017.1.

Smith, R. A., and C. D. Kummerow, 2013: A comparison of in situ, reanalysis, and satellite water budgets over the upper Colorado River basin. J. Hydrometeor., 14, 888-905, https:// doi.org/10.1175/JHM-D-12-0119.1.

Song, C., B. Huang, L. Ke, and Q. Ye, 2016: Precipitation variability in High Mountain Asia from multiple datasets and implication for water balance analysis in large lake basins. Global Planet. Change, 145, 20-29, https://doi.org/10.1016/j.gloplacha.2016.08.005.

Sylla, M., F. Giorgi, E. Coppola, and L. Mariotti, 2013: Uncertainties in daily rainfall over Africa: Assessment of gridded observation products and evaluation of a regional climate model simulation. Int. J. Climatol., 33, 1805-1817, https://doi.org/10.1002/joc.3551.

Tapiador, F. J., and Coauthors, 2012: Global precipitation measurement: Methods, datasets and applications. Atmos. Res., 104-105, 70-97, https://doi.org/10.1016/j.atmosres.2011.10.021.

Tarek, M., F. P. Brissette, and R. Arsenault, 2020: Evaluation of the ERA5 reanalysis as a potential reference dataset for hydrological modeling over North-America. Hydrol. Earth Syst. Sci., 24, 2527-2544, https://doi.org/10.5194/hess-24-2527-2020.

Tian, Y., and Coauthors, 2009: Component analysis of errors in satellite-based precipitation estimates. J. Geophys. Res., 114, D24101, https://doi.org/10.1029/2009JD011949.

Toté, C., D. Patricio, H. Boogaard, R. Van der Wijngaart, E. Tarnavsky, and C. Funk, 2015: Evaluation of satellite rainfall estimates for drought and flood monitoring in
Mozambique. Remote Sens., 7, 1758-1776, https://doi.org/ $10.3390 /$ rs70201758.

Vehviläinen, B., 1992: Snow cover models in operational watershed forecasting. Publications of the Water and Environment Research Institute 11, National Board of Waters and the Environment, $112 \mathrm{pp}$.

Vila, D. A., L. G. G. De Goncalves, D. L. Toll, and J. R. Rozante, 2009: Statistical evaluation of combined daily gauge observations and rainfall satellite estimates over continental South America. J. Hydrometeor., 10, 533-543, https://doi.org/10.1175/ 2008JHM1048.1.

Vogel, R., 2013: Quantifying the uncertainty of spatial precipitation analyses with radar-gauge observation ensembles. Scientific Rep. MeteoSwiss 95, 80 pp.

Weedon, G. P., G. Balsamo, N. Bellouin, S. Gomes, M. J. Best, and P. Viterbo, 2014: The WFDEI meteorological forcing data set: WATCH forcing data methodology applied to ERA-Interim reanalysis data. Water Resour. Res., 50, 7505-7514, https:// doi.org/10.1002/2014WR015638.

Wu, Z., Z. Xu, F. Wang, H. He, J. Zhou, X. Wu, and Z. Liu, 2018: Hydrologic evaluation of multi-source satellite precipitation products for the upper Huaihe River Basin, China. Remote Sens., 10, 840, https://doi.org/10.3390/rs10060840.

Yang, R., M. Ek, and J. Meng, 2015: Surface water and energy budgets for the Mississippi River basin in three NCEP reanalyses. J. Hydrometeor., 16, 857-873, https://doi.org/10.1175/ JHM-D-14-0056.1.

Yong, B., D. Liu, J. J. Gourley, Y. Tian, G. J. Huffman, L. Ren, and Y. Hong, 2015: Global view of real-time TRMM multisatellite precipitation analysis: Implications for its successor global precipitation measurement mission. Bull. Amer. Meteor. Soc., 96, 283-296, https://doi.org/10.1175/ BAMS-D-14-00017.1.

Zhu, H., Y. Li, Y. Huang, Y. Li, C. Hou, and X. Shi, 2018: Evaluation and hydrological application of satellite-based precipitation datasets in driving hydrological models over the Huifa River basin in Northeast China. Atmos. Res., 207, 28-41, https://doi.org/10.1016/j.atmosres.2018.02.022. 